\title{
Design of the Cruise and Flap Airfoil for the X-57 Maxwell Distributed Electric Propulsion Aircraft
}

\author{
Jeffrey K. Viken*, Sally A. Viken ${ }^{\dagger}$, Karen A. Deere ${ }^{\ddagger}$, Melissa B. Carter ${ }^{\S}$ \\ NASA Langley Research Center, Hampton, VA 23681, USA
}

\begin{abstract}
A computational and design study on an airfoil and high-lift flap for the X-57 Maxwell Distributed Electric Propulsion (DEP) testbed aircraft was conducted. The aircraft wing sizing study resulted in a wing area of $66.67 \mathrm{ft}^{2}$ and aspect ratio of 15 with a design requirement of $V_{\text {stall }}=58 \mathrm{KEAS}$, at a gross weight of $3,000 \mathrm{lb}$. To meet this goal an aircraft $C_{L, \max }$ of 4.0 was required. The design cruise condition is $150 \mathrm{KTAS}$ at 8,000 ft. This resulted in airfoil requirements of $c_{l} \sim 0.90$ for the cruise condition at $R e=2.35 \times 10^{6}$. A flapped airfoil with a $c$ l,max of approximately 2.5 or greater, at $R e=1.0 \times 10^{6}$, was needed to have enough lift to meet the stall requirement with the DEP system. MSES computational analyses were conducted on the GAW-1, GAW-2, and the NACA 5415 airfoil sections, however they had limitations in either high drag or low $c_{l, \max }$ on the cruise airfoil, which was the impetus for a new design. A design was conducted to develop a low drag airfoil for the $\mathrm{X}-57$ cruise conditions with high $c_{l, \text { max }}$. The final design was the GNEW5BP93B airfoil with a minimum drag coefficient of $c_{d}=\mathbf{0 . 0 0 5 3}$ at $c_{l}=\mathbf{0 . 9 0}$ and achieved laminar flow back to $69 \%$ chord on the upper surface and $62 \%$ chord on the lower surface. With fully turbulent flow, the drag increases to $c_{d}=\mathbf{0 . 0 1 2 0}$. The predicted maximum lift with turbulent flow is a $C_{l, \text { max }}$ of 1.95 at $\alpha=19^{\circ}$. The airfoil is characterized by relatively flat pressure gradient regions on both surfaces at $\alpha=0^{\circ}$, and aft camber to get extra lift out of the lower surface concave region. A $25 \%$ chord slotted flap was designed and analyzed with MSES for a $30^{\circ}$ flap deflection. Additional $30^{\circ}$ and $40^{\circ}$ flap deflection analyses for two flap positions were conducted with USM3D using several turbulence models, for two angles of attack, to assess near $c_{l, \max }$ with varied flap position. The maximum $c_{l}$ varied between 2.41 and 3.35. An infinite-span powered high-lift study was conducted on a GAW-1 constant chord $40^{\circ}$ flapped airfoil section with FUN3D to quantify the airfoil lift increment that can be expected from a DEP system. The $16.7 \mathrm{hp} /$ propeller blown wing increases the maximum $C_{L}$ from 3.45 to $C_{L}=$ 6.43, which is an effective $q$ ratio of 1.86 . This indicates that if the unblown high-lift flapped airfoil of the $\mathrm{X}-57$ airplane achieves a cl,max of 2.78, then the high-lift augmentation blowing could yield a sectional lift coefficient of approximately 4.95 at $c_{l, \text { max. }}$. Finally, a computational study was conducted with FUN3D on an infinite-span constant chord GAW-1 cruise airfoil to determine the impact of high-lift propeller diameter to wing chord ratio on the lift increment of the DEP system. A constant diameter propeller and nacelle size were used in the study. Three computational grids were made with airfoil chords of $0.5 *$ chord, $1.0 *$ chord, and $2.0 *$ chord. Results of the propeller diameter to wing chord ratio study indicated that the blown to unblown $C_{L}$ ratio increased as the chord was decreased. However, because of the increase in relative size of the high-lift nacelle to the wing, which impacted wing lift performance, the study indicated that a propeller diameter to wing chord ratio of 1.0 gives the overall best maximum lift on the wing with the DEP system.
\end{abstract}

Nomenclature

$c \quad$ chord, inches and nondimensional

\footnotetext{
* Aerospace Engineer, Aeronautics Systems Analysis Branch, Mail Stop 442, AIAA Senior Member.

${ }^{\dagger}$ Aerospace Engineer, Configuration Aerodynamics Branch, Mail Stop 499, AIAA Senior Member.

* Aerospace Engineer, Configuration Aerodynamics Branch, Mail Stop 499, AIAA Senior Member.

$\S$ Aerospace Engineer, Configuration Aerodynamics Branch, Mail Stop 499, AIAA Associate Fellow.
} 
reference chord

airfoil section drag coefficient

drag coefficient

induced drag coefficient

airfoil section lift coefficient

maximum airfoil section lift coefficient

lift coefficient for the wing

maximum lift coefficient for the wing

section pitching moment coefficient

pitching moment coefficient for the wing

pressure coefficient

drag force, $\mathrm{lb}$

Oswald efficiency factor

lift force, $\mathrm{lb}$

lift over drag ratio

maximum lift over drag ratio

freestream Mach number

critical $\mathrm{N}$-factor, to specify transition

propellers

dynamic pressure, $\mathrm{lb} / \mathrm{ft}^{2}$

Reynolds number based on reference chord

density, slugs $/ \mathrm{ft}^{3}$

reference area, $\mathrm{ft}^{2}$

freestream velocity, $\mathrm{ft} / \mathrm{s}$

weight, lb

wing loading, $\mathrm{lb} / \mathrm{ft}^{2}$

chordwise location

$\Delta \mathrm{x} / \mathrm{c}_{\mathrm{ref}}-\mathrm{x} / \mathrm{c}_{\mathrm{ref}}$ translation

spanwise station, butt-line, inches

nondimensional first node height in boundary layer

nondimensional first cell centroid height in boundary layer

$\Delta \mathrm{y} / \mathrm{c}_{\mathrm{ref}}-\mathrm{y} / \mathrm{c}_{\mathrm{ref}}$ translation

initial VGRID spacing (first node off of surface in viscous grid layer)

$\underline{\text { Units }}$

$\mathrm{ft}$

feet

equivalent airspeed, knots

true air speed, knots

pounds

Direct Iterative Surface Curvature design method

Computational Fluid Dynamics

pseudo time advancement Courant-Friedrichs-Lewy

Distributed Electric Propulsion

General Aviation

Hybrid-Electric Integrated Systems Testbed

high-lift

horse power

equivalent airspeed (knots)

true airspeed (knots)

Leading-Edge Asynchronous Propulsion Technology

revolutions per minute

Spalart-Allmaras one equation turbulence model

Spalart-Allmaras one equation turbulence model with rotation and curvature correction and the quadratic constitutive relation

SARC+QCR

SAQCR

Spalart-Allmaras one equation turbulence model with the quadratic constitutive relation

SCEPTOR

SST

Scalable Convergent Electric Propulsion Technology and Operations Research

Menter's Shear Stress Transport model

TetrUSS Tetrahedral Unstructured Software System

Symbols:

delta

3.14159

\section{Introduction}


The NASA New Aviation Horizons initiative has a goal to accelerate the adoption of advanced green aviation technologies by industry. Cleaner, quieter, and even faster airplanes will be developed with the NASA Xplane research approach. The X-57 Maxwell, or Scalable Convergent Electric Propulsion Technology and Operations Research (SCEPTOR) airplane will be one of several airplanes worthy of the X-plane status. The goal of this X-plane technology demonstrator is to prove that Distributed Electric Propulsion (DEP) can provide typical takeoff and landing performance with a smaller wing, increasing cruise efficiency. Aircraft with DEP will have a smaller cruise wing, lower cruise drag, and consume 4.8 times less energy than the baseline, avgas-fueled airplane. ${ }^{1}$ To assist takeoff and landing with a smaller cruise wing, electrically-driven, high-lift propellers are mounted on nacelles upstream of the wing leading edge to increase dynamic pressure over the wing for more lift. The advanceddesign propellers will fold smoothly onto the nacelle during cruise flight.

The motivation to utilize the DEP system comes from the understanding that because of competing design requirements, most often the wings of General Aviation (GA) aircraft are larger than they need to be for the cruise condition. A certification requirement for single engine GA aircraft is to meet a 61 KEAS stall speed. To meet the stall speed requirement the typical wing loading $(W / S)$ is between $15.0 \mathrm{lb} / \mathrm{ft}^{2}$ and $20.0 \mathrm{lb} / \mathrm{ft}^{2}$, which yields a typical cruise lift coefficient $\left(C_{L}\right)$ between 0.20 and 0.30 . A wing with a $C_{L, \max }$ capability equal to about 1.5 to 2.0 , and a lift coefficient at a maximum lift to drag ratio $\left(L / D_{\max }\right)$ in the range of $C_{L}=0.6$ to $C_{\mathrm{L}}=0.9$, has more wetted area than needed for a 'cruise optimized' configuration. The goal of the DEP system is to increase the $C_{L, \max }$ of the aircraft takeoff and landing configurations by increasing the local dynamic pressure $(q)$ over a smaller wing, and thereby decreasing skin friction drag at cruise (by reducing wing wetted area). The challenge is to design an airfoil/flap/DEP system that meets all of the mission requirements that the larger GA wing meets. The design of a smaller wing with less wetted area at cruise does cause additional design challenges. One design challenge is increased induced drag $\left(C_{D i}\right)$, which varies as $C_{D i}=C_{L}^{2} /(\pi * A R * e)$, where $A R$ is aspect ratio and e is Oswald efficiency factor. For example, if the design $C_{L}$ is tripled, from $C_{L}=0.25$ to $C_{L}=0.75$, because the wing area $(S)$ is reduced by a factor of $3\left(\mathrm{~S}_{\mathrm{DEP}}=\mathrm{S} / 3\right)$, then for the same aspect ratio wing, the induced drag $\left(q^{*} C_{D i} * S\right)$ is increased by a factor of $3(9.0 / 3.0=3)$. This drives the DEP configurations to need high aspect ratio wings to minimize the increase in induced drag. Note this design trade-off also results in smaller chord wings. If the cruise $C_{L}$ is increased by a factor of 3 , and the aspect ratio is increased by a factor of 2 to reduce induced drag, then the average chord scales down by a factor of the $\sqrt{6}=0.41$. Therefore, an additional design challenge is to design a high cruise airfoil section lift coefficient $\left(c_{l}\right)$ for low Reynolds numbers, that minimizes boundary layer separation and the accompanying drag penalty. Also, as the chord is reduced, for a given airfoil thickness ratio, the absolute airfoil thickness is reduced in direct proportion to the chord. This results in reduced spar thickness. With a smaller spar depth, reduced torsion box volume, and increased span, the wing stiffness now is of more concern. Additional work needs to be conducted to ensure the structure is stiff enough so that divergence and flutter speeds are above the flight envelope.

\section{Background}

This paper will discuss the results from computational studies for the design of the airfoil and flap for the DEP X-57 airplane configuration at cruise and takeoff/landing conditions. At the beginning of this design study the only previous computational work that had been conducted for DEP systems was STAR-CCM+ computational studies for the Leading Edge Asynchronous Propulsion Technology (LEAPTech) wing tested on the Hybrid-Electric Integrated Systems Testbed (HEIST) truck (Fig. 1). ${ }^{2}$ The HEIST wing consisted of the NASA GAW-1 airfoil with a full span $30 \%$ Fowler flap ${ }^{3}$ deflected $40^{\circ}$. There were 18 DEP propellers mounted on electric motors in nacelles upstream of the wing leading edge. The GAW-1 airfoil/flap was chosen because of the high-lift capabilities of the cruise airfoil $\left(c_{l, \max }=2.0\right.$ at $R e=2.1$ million) and the $40^{\circ}$ Fowler flap $\left(c_{l, \max }=3.6\right.$ at $R e=2.2$ million). Experimental wind tunnel test data existed for both the cruise airfoil ${ }^{4}$ and Fowler flap airfoil ${ }^{5}$ that verified these high-lift results. Note, at the time of the SCEPTOR airfoil/flap design, the HEIST test had not been conducted, and there was no test data available to use to aid in the design of a new DEP wing.

For the X-plane demonstrator, a new DEP wing system designed for technology development will be installed on a Tecnam P2006T aircraft (Fig. 2) by removing the original wing and installing the cruise optimized DEP wing (Fig. 3). The main performance goals are a $58 \mathrm{KEAS}$ stall speed at 3,000 lb gross weight (equivalent to the scaled gross weight of the original P2006T), while achieving a cruise speed of 150 KTAS at 8,000 ft, with 4.8 times lower energy use compared to the original P2006T aircraft. The design sizing study of the wing was presented in Reference 1. The final sizing study resulted in a wing design with a wing loading $(W / S)$ of $45 \mathrm{lb} / \mathrm{ft}^{2}$, a wing area $(S)$ of $66.67 \mathrm{ft}^{2}$, and an aspect ratio $(A R)$ of 15 , yielding a cruise $C_{L}$ of 0.75 on the new DEP wing. The original Tecnam P2006T aircraft has a wing loading of $16.365 \mathrm{lbs} / \mathrm{ft}^{2}$, a wing area of $158.88 \mathrm{ft}^{2}$, an aspect ratio of 8.8 , and a 
cruise $C_{L}$ of 0.275 . The comparison of wing sizing parameters between the Tecnam P2006T and X-57/SCEPTOR aircraft comparison is summarized in Table 1.

Aerodynamically, the optimization process drove the wing design to very high wing loadings and aspect ratios. Early in the design process, estimates were made that an airfoil with a cruise lift coefficient of approximately 1.0 would be needed, while still achieving an acceptable $c_{l, \max }$ for takeoff and landing. The initial investigation into the design of a cruise $c_{l}=1.0$ airfoil will be discussed first. However, the final X-57 wing sizing resulted in an airfoil with a reduced cruise lift coefficient of approximately $c_{l}=0.90$, because the wing area reduction and aspect ratio increase of the final design were limited due to structural and aeroelastic design considerations. Note that to increase cruise efficiency, the new airfoil section was designed to be able to achieve laminar flow. For an efficient wing, an airfoil needs to have low drag in a $c_{l}$ range around the 'target $c_{l}$ '. At cruise, with an aircraft lift coefficient of 0.75 , the spanwise section lift coefficient varies from $0.7 \leq c_{l}<0.9$. Additionally, there needs to be some margin to maneuver around the cruise point. To achieve the stall speed goal for the X-57 aircraft, a $C_{L, \max }$ of 4.0 is required from the wing and DEP high-lift system. To achieve the target airplane $C_{L, \max }$, the blown high-lift flap needs to provide section lift coefficients on the order of $c_{l, \max }>5.0$. The DEP system propellers increase the local velocity (and dynamic pressure) of the flow over the wing and the change in velocity $(\Delta V)$ acts as a multiplier to the basic lift. The wing does need an effective high-lift flap to maximize the final $c_{l, \max }$. The final X-57 high-lift wing design incorporated a $25 \%$ chord slotted flap deflected $30^{\circ}$ by extending the flap about a single-pivot displaced hinge.

\section{Computational Analysis Codes and Grid Generation Tools}

During the design process of the cruise airfoil and flap, tow-dimensional (2-D) and three-dimensional (3-D) computational analysis codes and grid generation tools were used, which are described below.

\section{A. MSES}

MSES $^{6,7}$ is a coupled viscous/inviscid Euler method for 2-D analyses. The steady-state finite volume equations are derived from the integral form of the mass, momentum, and energy conservation laws to obtain correct treatment of shocks. The streamline-based Euler discretization and a two-equation integral boundary layer formulation are coupled together through the displacement thickness and solved simultaneously by a full Newton method.

\section{B. CDISC}

Design iteration of the new high $c_{l}$ airfoil included the use of CDISC ${ }^{8}$ to tailor the flap pressure regions, the pressure transition into the pressure recovery, and the decelerations in the pressure recovery. CDISC incorporates flow and geometric constraints into the Constrained Direct Iterative Surface Curvature design method. This is an iterative method in which the flow is computed around an input airfoil geometry and the difference between the computed pressures and input target pressures is used to compute an estimate for the change in the surface geometry to match the target pressures. The process is repeated for a specified number of iterations or until a user-defined constraint is reached to within an input tolerance.

\section{USM3D}

The USM3D code is a parallelized three-dimensional, cell-centered, finite volume discretization, Reynoldsaveraged Navier-Stokes flow solver, which is part of the NASA Tetrahedral Unstructured Software System $(\text { TetrUSS })^{9,10}$ developed at NASA Langley Research Center. Inviscid flux quantities are computed across each tetrahedral cell face using various upwind schemes, such as the Roe's flux-difference-splitting (FDS) technique used for this study. ${ }^{11}$ Three turbulence models were used for the analyses conducted; the Spalart-Allmaras (SA) one equation turbulence model ${ }^{12}$, the Spalart-Allmaras one equation turbulence model with the mean stress-strain Quadratic Constitutive Relation (SAQCR) ${ }^{13}$, and the Menter's Shear Stress Transport (SST) model. ${ }^{14}$

\section{FUN3D}

FUN3D is a node-based, finite-volume discretization, Reynolds-averaged Navier-Stokes flow solver. The inviscid fluxes are obtained on the faces of each control volume using the flux-difference-splitting technique of 
Denver, CO

Roe. ${ }^{11}$ Fully turbulent predictions were computed with FUN3D ${ }^{18}$ using the Spalart-Allmaras one equation turbulence model ${ }^{12}$ with rotation and curvature correction and the mean stress-strain Quadratic Constitutive Relation (QCR). ${ }^{13}$

\section{E. GridTool and VGRID}

GridTool and VGRID software, both part of TetrUSS ${ }^{9,10}$, were used to generate tetrahedral meshes. GridTool was used to take the splined set of airfoil coordinates, and create the curves, patches and grid topology (sources) to define the surface and farfield outer boundaries for grid generation with VGRID. The VGRID grid generator is based on the Advancing Layers Method for generation of thin-layer 'viscous cells' and the Advancing Front Method for generation of the 'inviscid' field cells.

\section{F. Q2D}

One-cell wide tetrahedral element grids were generated using the Q2D grid generation method. ${ }^{15}$ Q2D generates a 2-D unstructured grid around an airfoil section using VGRID, and then prisms are extruded from the triangular faces in the spanwise direction from the symmetry plane. These prisms are then split into tetrahedral cells to form the tetrahedral element grid.

\section{Grid Generation, Computational Scheme, and Convergence}

\section{A. High-Lift Flap Design}

One-cell wide tetrahedral element grids were generated for the airfoil and flap geometries (discussed in Section VII) using the Q2D grid generation method. ${ }^{15}$ Each grid airfoil section was nondimensionalized with a reference chord $\left(c_{r e f}\right)$ of 1.0 , and a reference span of 0.02 , with the moment reference center located at the quarter chord. The farfield boundaries extended approximately 50 chord lengths from the airfoil along the x- and $\mathrm{z}$-axes. The airfoil surface was defined with a viscous no-slip boundary condition, the grid sidewalls were defined as a reflection plane with the tangency boundary condition, and the farfield boundaries utilized the Reimann invariants boundary condition. A flat-plate, turbulent boundary layer calculator was used with chord length, Reynolds number based on reference chord length, target $y^{+}$, and a target number of layers of cells within the boundary layer to specify the first cell height and expansion rate of the grid. An initial spacing for the first node off of the surface in the viscous grid layer $\left(\delta_{l}\right)$ was prescribed in order to achieve a $y^{+}=2$ at the first node, which is a $\mathrm{y}^{+}{ }_{\mathrm{cc}}=0.5$ at the first cell centroid for the grids, as these grids were run with USM3D, a cell-centered flow solver. The number of layers of cells within the boundary layer was specified as 30 . Reference 16 recommends a $y^{+}=1.0$ for coarse mesh resolution, $y^{+}=0.67$ for medium mesh resolution, $y^{+}=0.44$ for a fine mesh resolution, and $y^{+}=0.3$ for an extra-fine mesh resolution. The actual $y^{+}$values from the CFD solutions were less than 0.58 .

All the cases were run with steady-state calculations that used a local time step pseudo-time advancement scheme. The pseudo-time advancement Courant-Friedrichs-Lewy (CFL) number was ramped up from 1 to 150 over 1000 iterations. For the $\mathrm{f} 30 \mathrm{a}$ airfoil cases, a second-order backward difference scheme and pseudo-Newton method was also used for time-accurate temporal time integration as a check to compare with the steady-state calculations. All steady-state solutions converged with at least 4 orders of magnitude reduction in the mean flow residuals. The mean flow residuals of the time-accurate solutions decreased approximately 2 orders of magnitude. The steady-state solutions were monitored for convergence with a standard deviation of $c_{l}$ less than $0.000072, c_{d}$ less than 0.0000121 , and $c_{m}$ less than 0.000022 , over an interval of 5,000 iterations.

\section{B. Assessing Blown Flapped Airfoil Performance}

A tetrahedral mesh of a wing section with a flap was generated with GridTool and VGRID software (discussed in Section VIII) for unblown (no power) and blown (power) analyses. The grid was nondimensionalized with a reference chord of 1.0 and reference span of 0.8548 , resulting in a wing section reference area of 0.8548 . The reference span of 0.8548 represents the nondimensional distance between the nacelle centerlines of a series of DEP 
propellers across a wing, and is also equivalent to the propeller diameter. The farfield boundaries extended approximately 100 chord lengths from the airfoil surface along the $\mathrm{x}$ - and $\mathrm{z}$-axes. The wing section and nacelle were defined with a viscous no-slip boundary condition, and the grid sidewalls enforced a symmetry boundary condition for the y-Cartesian plane, to simulate an infinite-span grid with pairs of two counter-rotating propellers. The farfield boundaries utilized the Reimann invariants boundary condition. A flat-plate, turbulent boundary layer calculator was used with chord length, Reynolds number based on reference chord length, target $y^{+}$, and a target number of layers of cells within the boundary layer to specify the first node height and expansion rate of the grid. The initial target first node height of the mesh was to obtain a $y^{+}=0.67$, as recommended in Reference 16 for a medium mesh resolution. However, the actual blown wing section solution $y^{+}$values were higher than expected due to the influence of the propeller slipstream over the surface. Therefore, the target first node height of the mesh was defined as $y^{+}=0.3$. The number of layers of cells within the boundary layer was specified as 27 . The mesh size was approximately 15.6 million mesh points. The actual $y^{+}$values for the unblown wing section solutions were less than 1.0 , except right at the leading-edge region with peak $y^{+}$values of 1.15. The actual $y^{+}$values for the blown wing section were less than 1.0 also, except along the wing leading-edge region, with peak $y^{+}$values of 1.7 due to the influence of the propeller 'blade-up' rotation.

All cases were run with steady state calculations that used a local time step pseudo-time advance schedule. The pseudo time advancement CFL number was ramped up from 1 to 100 over 100 iterations, except for cases near stall where CFL number was lowered to 25 . The flow solutions presented converged with at least 4 orders of magnitude drop for the mean flow residuals. The steady-state solutions were monitored for convergence with a standard deviation of $C_{L}$ less than $0.000027, C_{D}$ less than 0.000051 , and $C_{m}$ less than 0.000021 for the unblown (no power) cases, over an interval of 2,000 iterations. The steady-state solutions for the blown (power) wing converged with a standard deviation of $C_{L}$ less than $0.00007, C_{D}$ less than 0.000011 , and $C_{m}$ less than 0.000018 , over an interval of 2,000 iterations, except for one case that will be described in the results section.

\section{Investigating Propeller Diameter to Wing Chord on Blown High-Lift Performance}

Tetrahedral meshes were generated for wing sections with a nacelle with the GridTool and VGRID software, using nondimensional reference chords of $0.5,1.0$, and 2.0, with a reference span of 0.8548 (discussed in Section IX). Sources were defined near the nacelle and propeller disk region for tighter cell clustering of high-lift propeller cells. The farfield boundaries extended approximately 100 chord lengths from the airfoil along the $\mathrm{x}$ - and z-axes. The airfoil and nacelle surfaces were defined with a viscous no-slip boundary condition. The grid sidewalls enforced the symmetry boundary condition for the y-Cartesian plane, to simulate an infinite-span grid with pairs of two counter-rotating propellers. The farfield boundaries utilized the Reimann invariants boundary condition. A flatplate, turbulent boundary layer calculator was used with chord length, Reynolds number based on reference chord length, target $y^{+}$, and a target number of layers of cells within the boundary layer to specify the first node height and expansion rate of the grid. The target first node height of the mesh was specified to obtain a $y^{+}=0.67$, as recommended in reference 16 for a medium mesh resolution. The number of layers of cells within the boundary layer was specified as 27. Mesh sizes were approximately 10.6 million nodes for the grids with reference chord of 0.5 and 1.0, and approximately 11.1 million nodes for reference chord of 2.0. The actual $y^{+}$values from the solutions were less than 1.0 except along the leading-edge region of the wing, with peak $y^{+}$values of 1.84 for $c_{r e f}=$ $0.5, y^{+}$of 1.35 for $c_{r e f}=1.0$, and $y^{+}$of 1.15 for $c_{r e f}=2.0$ from the influence of the propeller 'blade up' rotation.

All the cases were run with the FUN3D flow solver, with steady-state calculations that used a local time step pseudo-time advancement scheme. The pseudo-time advancement CFL number was ramped up from 1 to 100 over 100 iterations. The flow solutions converged with at least 4 orders of magnitude reduction in the mean flow residuals. These steady-state solutions were monitored for convergence with a standard deviation of $C_{L}$ less than $0.000014, C_{D}$ less than 0.000003 , and $C_{m}$ less than 0.0000013 , over an interval of 2,000 iterations.

\section{Initial Airfoil Performance Investigation}

Since the airfoil chosen for the wing tested on the HEIST truck had a cruise airfoil with a high $c_{l, \max }$ and a powerful high-lift flap design, initial wing design investigations started with the GAW-1 (LS-0417) airfoil as a choice for the DEP airfoil selection for the X-57 aircraft. However, the GAW-1 (LS-0417) airfoil is a 17\% thick airfoil, and at the low Reynolds number of the smaller wing it poses a drag increase problem compared to thinner airfoil sections, due to separation at high $c_{l}$. Another airfoil of the same family, the GAW-2 (LS-0413), is a 13\% thick airfoil, which is a similar type of airfoil, with Fowler and slotted high-lift flap designs that has test data available. ${ }^{17}$ However, the $13 \%$ thick airfoil was not deemed acceptable because it was too thin structurally for the 
small X-57 wing.

As a compromise to design both an aerodynamic and structurally acceptable airfoil, a $15 \%$ thick airfoil, GAW215, was constructed by scaling the camber lines of the $13 \%$ and $17 \%$ thick airfoils. A comparison of the airfoil thickness, camber lines, and coordinates is shown in Figures 4 and 5. The section characteristics $\left(c_{l}, c_{d}\right.$, and $c_{m}$ ) of the three different thickness sections (GAW-1, GAW-2, and GAW215) were computed for free transition and fully turbulent cases using the MSES code and are presented in Figures 6 and 7, respectively. Examining Figure 6a, for the free transition cases, all three thickness sections (GAW-1, GAW-2, and GAW215) have about the same lift curve with the $15 \%$ and $17 \%$ sections having a slightly higher $c_{l, \max }$. In the fully turbulent cases, the $13 \%$ thick GAW-2 airfoil has a slightly higher $c_{l, \max }\left(\Delta c_{l}=0.02\right)$, as shown in Figure 7a. The three different thickness sections (GAW-1, GAW-2, and GAW215) do have differences in drag. For the free transition case, Figure 6b, the minimum drag varies from 0.0045 to 0.0050 , with the $13 \%$ thick GAW-2 having the lowest drag. This trend also exists outside the low drag bucket for high section lift coefficients, with the GAW-2 having the lowest drag above $c_{l}=0.9$. For the fully turbulent cases shown in Figure $7 \mathrm{~b}$, the drag of the 17\% thick GAW-1 is $10 \%$ higher than the $13 \%$ thick GAW-2 at its lowest value. Investigation of the drag plots reveals that the low drag range of these three airfoils is not in the desired target cruise $c_{l}$ range. As shown in Figure 6b, for the free transition cases, the lift coefficients for the low drag bucket of GAW-1, GAW-2, and GAW215 are all below the DEP wing projected cruise $c_{l}=0.90$. The drag at the projected cruise $c_{l}$ of 0.90 is nearly 1.8 times the drag of the minimum drag case of the GAW airfoils. The reason for this can be explained by examining the way the pressure distribution develops around the airfoil. As shown in Figure 8a, at $\alpha=0^{\circ}$, there is minimally accelerated flow (flat pressure distribution) on both surfaces of the GAW-1 airfoil, promoting laminar flow at this low Reynolds number. However, at $\alpha=4.5^{\circ}$, as shown in Figure 8b, it can be seen that an upper surface pressure peak develops in the leading-edge region of the GAW-1 airfoil that trips the flow from laminar to turbulent, increasing the drag to twice the minimum drag value. The pitching moment of the three GAW airfoil sections is shown for the free transition case in Figure 6c. There is very little difference between the pitching moments of the three thickness sections up to $\alpha=16^{\circ}$.

In pursuit of a lower drag airfoil at the projected cruise $c_{l}$, an investigation was also made on the NACA 5415 airfoil, an airfoil derived for high cruise $c_{l}$ from the NACA 4-digit series of airfoils. Examining the fully turbulent and free transition lift curves (Figs. 6a and 7a), the NACA 5415 airfoil has a lower $c_{l, \text { max }}$ than any of the GAW series airfoils, with $c_{l, \max }=1.67$, versus the GAW-1 airfoil with $c_{l, \max }$ of 1.8. Examining the free transition drag curves (Fig. 6b), the drag of the NACA 5415 airfoil at section lift coefficients near 0.9 is only $c_{d}=0.0067$, compared to the GAW215 $c_{d}$ of 0.090 . In the fully turbulent cases, the drag of the NACA 5415 airfoil is very similar to that of the GAW215 airfoil (Fig. 7b). The pressure distributions of the NACA 5415 airfoil for $\alpha=0^{\circ}$ and $4.0^{\circ}$ are shown in Figures 9a and 9b. The NACA 5415 airfoil does not promote long runs of laminar flow at $\alpha=0^{\circ}$ because the pressure distribution is only favorable up to $18 \%$ chord on the upper surface and $4 \%$ chord on the lower surface. Examining the lower surface pressure distribution for $\alpha=4^{\circ}$, it can be seen that the lower surface pressure peak disappears and there is $100 \%$ chord laminar flow. The transition location on the upper surface is $42 \%$ chord, making the $c_{l}=1.0$ case near the minimum drag condition for this airfoil. The NACA 5415 airfoil had lower drag at the target $c_{l}$ than any of the GAW airfoil sections, however the low maximum lift coefficient was a concern. Also, the NACA 5415 airfoil has no accompanying high-lift flap design to use.

\section{High Cruise Lift Coefficient Airfoil Design}

Based upon the initial investigation, and realizing that a high-lift flap was needed for the DEP design, a new airfoil and flap were designed. The design goals were: (1) $15 \%$ thick - as a compromise between aerodynamic and structural considerations, (2) long runs of favorable/flat pressure gradients to promote laminar flow, (3) design in aft camber to carry lift and minimize the pressure recovery on the airfoil upper surface, (4) target cruise $c_{l}=0.9$ to 1.0 , and (5) acceptable $c_{d}$, achieving laminar flow, but having no separation at the cruise condition when the flow is fully turbulent.

Design iteration of the new high $c_{l}$ airfoil included the use of CDISC ${ }^{8}$ to tailor the flap pressure regions, the pressure transition into the pressure recovery, and the decelerations in the pressure recovery. The new high $c_{l}$ airfoil was designed using the following procedure: (1) scale the camber line of the GAW airfoil series, (2) adjust a simple flap to add aft camber, (3) adjust the angle of attack to minimize the leading-edge pressures peaks on each surface, (4) run CDISC to develop smooth flat pressure coefficient $\left(C_{P}\right)$ distributions on each surface, (5) run CDISC to tailor and smooth the aft pressure recovery regions, especially the initial deceleration region, and (6) smooth the airfoil leading edge by curve fitting with polynomials. The new airfoil was designed with a combination of the previous procedures resulting set of airfoil coordinates, which was analyzed in MSES to assess if further design was needed. The resulting $15 \%$ thick airfoil (GNEW5B) has a cruise $c_{l}$ of 1.018 at $\alpha=0^{\circ}$ and the minimum drag is $c_{d}=0.00551$ 
(Fig. 10). The airfoil is characterized by relatively flat gradient regions on both surfaces at $\alpha=0^{\circ}$, and aft camber to get extra lift from the lower surface concave region, helping with upper surface boundary layer attachment at high sectional lift coefficients. The GNEW5B airfoil has a higher $c_{l, \text { max }}$ when compared to the other airfoils, for both the free transition and the fully turbulent cases, as shown in Figures 6a and 7a. It has a low drag bucket between $c_{l}=$ 0.85 and $c_{l}=1.2$ for the free transition case (Fig. 6b). For the fully turbulent case the drag is comparable to the other $15 \%$ thick airfoils of lower camber (Fig. $7 \mathrm{~b}$ ).

As stated before, the final X-57 Maxwell wing sizing considerations limited the allowable wing area reduction and the aspect ratio increase due to structural and aeroelastic limitations. The resulting final design cruise lift coefficient for the wing is a lift coefficient $\left(C_{L}\right)$ of 0.75 , resulting in an airfoil design lift coefficient $\left(c_{l}\right)$ of approximately 0.90. As can be seen by examining the low drag bucket of the GNEW5B airfoil (Fig. 6b), this new cruise $c_{l}$ of 0.90 is near the bottom of the low drag bucket. The camber line of the GNEW5B airfoil was scaled by 0.87 and 0.93 to obtain an airfoil at the new target cruise $c_{l}$ with available operating margin. The resulting airfoil contours, GNEW5BP87 and GNEW5BP93, are compared with the GNEW5B airfoil in Figure 11. The scaling of the camber line effectively scales the design $c_{l}$ of the airfoil at $\alpha=0^{\circ}$. The pressure distributions of the two different cambered airfoils (GNEW5BP87 and GNEW5BP93) are compared to the baseline airfoil (GNEW5B) in Figure 12. The camber scaling shifts the low drag bucket of the GNEW5BP93 airfoil and provides a range of $c_{l}$ around the target $c_{l}$ of 0.9 with low drag (Fig. 13). The reduction in the camber line did slightly reduce the maximum lift coefficient as can be seen in the $c_{l}$ versus $\alpha$ curve in Figure 14. The airfoil that was used for the X-57 cruise wing design is the 93\% scaling of the camber line, the GNEW5BP93 airfoil. The GNEW5BP93 airfoil has a minimum drag coefficient $\left(c_{d}\right)$ of 0.0053 at $c_{l}=0.90$ with laminar flow to $69 \%$ chord on the upper surface and $62 \%$ chord on the lower surface. The drag increases to $c_{d}=0.0120$ for fully turbulent flow. The predicted lift coefficient with turbulent flow is $c_{l, \max }=1.95$, at $\alpha=19^{\circ}$.

\section{High-Lift Flap Design}

After the design of the X-57 cruise airfoil, a high-lift flap was developed. The HEIST wing airfoil geometry was the GAW- 1 airfoil with a $30 \%$ chord Fowler flap deflected $40^{\circ} ., 5$ The Fowler flap concept needs a flap track mechanism to deploy the flap to its optimum position. For the X-57 Maxwell DEP demonstrator, a single pivot flap extension mechanism was desired because of the simplicity of the system, and a flap track mechanism would only be used if needed. Wind tunnel results were available for the GAW-2 13\% thick airfoil with both a $25 \%$ chord slotted flap and a 30\% chord Fowler flap. ${ }^{17}$ The maximum lift coefficient of the GAW-2 airfoil with the $25 \%$ slotted flap at a deflection of $30^{\circ}$ was $c_{l, \max }=3.48$, versus $c_{l, \max }=3.65$ with the $30 \%$ chord Fowler flap deflected $30^{\circ}$. With a slotted-flap design, the option was available to employ either a single pivot or a flap track extension mechanism. Therefore, the $25 \%$ chord slotted flap was chosen for the design. Since the X-57 Maxwell schedule and budget did not include developmental testing of the high-lift flap, and because the GAW-2 slotted flap had good high-lift performance, the resulting slotted flap design was tailored from the forward portion of the GAW-2 slotted flap. Most of the aft portion of the flap was determined by the cruise airfoil coordinates. To develop the flap, an algorithm was developed that scaled the leading edge of the GAW-2 25\% chord slotted flap and used the forward camber distribution to define a new flap geometry, within the external coordinates of the GNEW5BP93B airfoil. The coordinates of the airfoil and flap deflected $30^{\circ}$ and $40^{\circ}$ are shown in Figure 15. The target gap and overlap dimensions used were those optimum for the GAW-2 25\% chord slotted flap in Reference 17, because there was going to be no wind tunnel optimization of the flap position relative to the airfoil. The pressure distribution of the GNEW5BP93B with the $30^{\circ}$ flap deflection configuration computed with the MSES code is shown in Figure 16a for $\alpha=0^{\circ}\left(\mathrm{R}=1.0 \times 10^{6}\right)$ and Figure $16 \mathrm{~b}$ for $\alpha=10^{\circ}\left(\mathrm{R}=1.3 \times 10^{6}\right)$. The section characteristic plots $\left(c_{l}, c_{m}\right.$, and $\left.c_{d}\right)$ for the GNEW5BP93B airfoil with the $30^{\circ}$ flap configuration are presented in Figure 17. The maximum $c_{l}$ computed with the MSES code was 2.75 at $\alpha=8^{\circ}$ and $9^{\circ}$. It was not possible to get converged solutions from the MSES airfoil analysis at a $40^{\circ}$ flap deflection for the cases tried.

Fully turbulent flow analyses were then conducted with the USM3D ${ }^{9,10}$ flow solver for two different flap deflections and with three different turbulence models. The three turbulence models were used for the analyses to get an understanding of the uncertainty in the CFD predictions; the Spalart-Allmaras (SA) one equation turbulence model $^{12}$, the Spalart-Allmaras one equation turbulence model with the mean stress-strain Quadratic Constitutive Relation (SAQCR) ${ }^{13}$, and the Menter's Shear Stress Transport (SST) model. ${ }^{14}$ The analyses were conducted for a $30^{\circ}$ and $40^{\circ}$ flap deflection of the GNEW5BP93B airfoil with two different gap/overlap locations each (referenced as the $\mathrm{f30}, \mathrm{f30a}, \mathrm{f40}$, f40a geometries). The flap deflection and location information for these cases are presented in Table 2, with the coordinates of the relative flap locations represented in Figures 18a and 18b. The f30 and f40 flap positions were determined by the gap and overlap location of the optimized flap locations for the slotted flap in 
reference 17. The f30a and f40a configurations had the overlap increased and a smaller gap. This alternate location was based upon recommendations from colleagues who had some experience analyzing high-lift systems.

One-cell wide tetrahedral element grids were generated for each of the airfoil geometries (f30, f30a, f40, and f40a) using the Q2D grid generation method as described previously in Section IV, Grid Generation, Computational Scheme, and Convergence. The mesh sizes for the f30, f30a, f40, and f40a grids are shown in Table 3. The actual $y^{+}$values from the CFD solutions were less than 0.58. The airfoil configuration studies were conducted with a freestream flow of $M_{\infty}=0.096$ and $R e=1$ million based on the reference chord of 1 . The $\mathrm{f} 30$ and f30a geometries were analyzed at two angles of attack, $\alpha=6^{\circ}$ and $\alpha=10^{\circ}$, while f40 and f40a were analyzed at $\alpha=$ $10^{\circ}$ only. The lift, drag and pitching moment coefficient results for f30, f30a, and f40a (only $\alpha=10^{\circ}$ ) using the three turbulence models (SA, SAQCR, and SST) are presented in Table 4. The data for the f40 geometry cases are not shown as these cases did not converge. Graphical charts of the predicted lift coefficients are also shown for the f30 and f30a configurations at $\alpha=6^{\circ}$ (Fig. 19a), and f30, f30a, and f40a at $\alpha=10^{\circ}$ (Fig. 19b). At $\alpha=10^{\circ}$, the $c_{l}$ values vary between 2.78 and 3.23 for the $30^{\circ}$ flap deflection cases, and between 2.74 and 3.35 for the $40^{\circ}$ flap case. The SA turbulence model analysis predicts the highest lift coefficient for each configuration and angle of attack analyzed, followed by the SAQCR turbulence model. The exception is the $\mathrm{f} 30$ geometry case at $\alpha=10^{\circ}$ in which the SST turbulence model predicts higher lift coefficient than the SAQCR turbulence model. Overall, the f30a geometry generates a higher lift coefficient than the f30 geometry. At $\alpha=10^{\circ}$, with the SA and SAQCR turbulence models the f40a geometry provides just a slight improvement over both $30^{\circ}$ flap deflection cases. Time accurate solutions were also conducted for the f30a geometry at $\alpha=6^{\circ}$ with a nondimensional time step of 0.1 and 20 subiterations. Figure 20 shows a comparison of the steady state results with the time accurate results, and the differences between the approaches are less than 0.14 percent for all three turbulence models. Pressure coefficient contour plots with streamlines are shown in Figures 21a, 21b, and 21c for the f30, f30a, and f40a geometries at $\alpha=$ $10^{\circ}$, respectively. Note the difference in predicted flow separation and recirculation region over the flap element for each configuration and each turbulence model (Table 5). Figure 22 shows the pressure coefficient distributions on the f30a geometry at $\alpha=10^{\circ}$, for each of the turbulence models analyzed. The SA turbulence model predicts a slightly higher negative pressure peak on the main element and flap than the SAQCR turbulence model, with the least negative pressure peak predicted by the SST turbulence model. The $c_{l}$ for the SA turbulence model is 3.23, whereas for the SST turbulence model the $c_{l}$ is only 2.78. The large difference in lift coefficient can be explained by examining the streamline plots in Figure 21. The SST turbulence model has a significantly more pronounced recirculation region behind the upper surface of the flap than the SA and SAQCR turbulence models, resulting in a much lower lift coefficient. The main element streamlines over the upper surface are not turned downward by the flap in the SST solution, as they are in the SA and SARQCR solutions. Figure 23 shows the pressure coefficient distributions on the three geometries using the SAQCR turbulence model at $\alpha=10^{\circ}$. Comparing the $\mathrm{f30}$ and f30a pressure distributions, having the same flap deflection but different gap/overlap distances, the f30a geometry has a higher negative pressure peak over the main element and lower pressure peak over the flap than the f30 geometry. For the $\mathrm{f3} 0$ geometry, which has the highest negative pressure peak on the flap, the last $65 \%$ chord of the flap is separated as indicated by a flap $C_{P}$ distribution in Fig. 23 and recirculating streamlines in Fig. 21a (middle)). The f30 flap geometry yields a $c_{l}$ of 2.845, while the f30a flap geometry has a $c_{l}$ of 3.122. Comparing the f30a and f40a geometries, which have similar gap/overlap distances but different flap deflections, both geometries have similar pressure distributions over the main element, but the f40a has a higher negative pressure peak on the flap than the f30a (Fig. 23) and carries a little higher lift than the f30a.

\section{Assessing DEP Blown Flapped Airfoil Performance}

To achieve the X-57 stall speed goal, a $C_{L, \max }$ of 4.0 is required from the wing and DEP high-lift system. This requires a significant lift augmentation from the DEP system over and above the unblown flapped wing $C_{L, \max }$. During the design process, the exact capability of the DEP high-lift augmentation system to increase the $c_{l, \max }$ above the unblown airfoil and flap was not known, especially since the impact of the high-lift nacelle on lift was unknown. To help quantify the blown lift increment on a flapped airfoil and be able to apply the increment to the wing design, preliminary powered CFD analyses were conducted using FUN3D ${ }^{18}$. The CFD geometry was a constant chord airfoil section cut from the HEIST testbed wing (GAW-1 airfoil) with a $40^{\circ}$ flap deflection and a high-lift propeller mounted on a nacelle upstream of the wing leading edge. The airfoil cut was taken from wing station $\mathrm{y}=102.152$ " with a local chord of 20.5733" (Fig. 24) and with an incidence of $3.5^{\circ}$ when the nacelle is aligned with the flow. This is defined as the $\alpha=0^{\circ}$ position. The airfoil cut was then extruded, with no taper (as shown in Fig. 25), to form a wing for computational analyses. The wing section with nacelle will be referred to as the HEIST wing section in the following discussions. The tetrahedral mesh of the HEIST wing section was generated with GridTool 
and VGRID software, as described previously in Section IV, Grid Generation, Computational Scheme, and Convergence. Fully turbulent predictions were computed with FUN3D ${ }^{18}$ using the Spalart-Allmaras one equation turbulence model ${ }^{12}$ with rotation and curvature correction and the mean stress-strain Quadratic Constitutive Relation (QCR). ${ }^{13}$ The powered FUN3D simulations for this study used an actuator disk representation for the high-lift propeller, with thrust and torque coefficient data as inputs into the actuator disk model. The thrust and torque coefficient data were derived from the XROTOR ${ }^{19}$ blade element momentum analyses. The infinite-span wing analyses were conducted with a freestream flow of $M_{\infty}=0.0962, R e=1$ million (based on reference chord of 1.0 ), for an angle of attack range from $-4^{\circ}$ to $12^{\circ}$. The actuator disk model represented the power condition of 16.7 $\mathrm{hp} /$ prop and $6147 \mathrm{RPM}$, with thrust $=44.74 \mathrm{lb}$, and torque $=14.23 \mathrm{lb}-\mathrm{ft}$. The steady-state solutions for the blown (power) wing converged with a standard deviation of $C_{L}$ less than $0.00007, C_{D}$ less than 0.000011 , and $C_{m}$ less than 0.000018 , over an interval of 2,000 iterations, except at $\alpha=8^{\circ}$. At $\alpha=8^{\circ}$, just past stall, the standard deviation for $C_{L}$ was $0.00107, C_{D}$ was 0.000270 , and $C_{m}$ was 0.0001389 . The unblown (no power) case at $\alpha=6^{\circ}$ and the blown-wing (power) case at $\alpha=10^{\circ}$ case did not converge with steady-state local time stepping. The unblown $\alpha=$ $6^{\circ}$ case was run with a second-order backward difference scheme for time-accurate temporal time integration and converged.

The predicted lift, drag, and pitching moment coefficients are presented in Figure 26 for the unblown and blown high-lift HEIST wing section with a $40^{\circ}$ flap deflection. Note, the airfoil incidence of $3.5^{\circ}$ is not reflected in the angle of attack. It can be seen that the blown wing ( $16.7 \mathrm{hp} / \mathrm{prop})$ increases the maximum $C_{L}$ from 3.45 to 6.43 , which is an effective $q$ ratio of 1.86 . This indicates that if the unblown high-lift flapped airfoil of the X-57 airplane achieves a $c_{l, \max }$ of 2.78 (the lowest value of the f30a USM3D CFD computations), then the high-lift augmentation blowing could yield a sectional lift coefficient of approximately 4.95 at $c_{l, \max }$. The blowing lift augmentation does come with an increase in drag (Fig 26b), from $C_{D}=0.08159$ to $C_{D}=0.41156$ at $\alpha=0^{\circ}$, and $C_{D}=0.28752$ to $C_{D}=$ 0.46914 at $\alpha=6^{\circ}$, for example. The blowing lift augmentation also comes with large impact on pitching moment (Fig. 26c), from $C_{m}=-0.73205$ to $C_{m}=-1.45015$ at $\alpha=0^{\circ}$, and $C_{m}=-0.55265$ to $C_{m}=-1.03653$ at $\alpha=6^{\circ}$, for example. Figures $27 \mathrm{a}$ and $27 \mathrm{~b}$ show upper surface pressure coefficient contour plots of the HEIST wing section with $40^{\circ}$ flap deflection, unblown and blown, respectively for $M_{\infty}=0.0962, \operatorname{Re}=1$ million, at $\alpha=0^{\circ}$ and $\alpha=4^{\circ}$. For the unblown wing (no power) case at $\alpha=0^{\circ}$, the upper surface pressure coefficient contours look fairly symmetrical across the nacelle centerline, whereas for $\alpha=4^{\circ}$ case the pressure coefficient contours become less symmetrical across the span as the flow moves further aft from leading-edge region. Note, the grid sidewall boundaries enforced a symmetry boundary condition for the y-Cartesian plane, to simulate an infinite-span grid with pairs of two counter-rotating propellers. For the blown wing (power) cases at $\alpha=0^{\circ}$ and $\alpha=4^{\circ}$, the higher negative pressure peaks at the main element leading edge are influenced by the swirl induced by the propeller. Propeller 'blade up' rotation is left of nacelle looking into the incoming flow (Fig. 27b). Pressure coefficient distributions were extracted at $\alpha=0^{\circ}$ and $\alpha=4^{\circ}$ for two spanwise stations corresponding to $1 / 8^{\text {th }}$ and $7 / 8^{\text {th }}$ of the propeller diameter: Station 1 (blade up) and Station 2 (blade down), as shown in Figure 28. Note the width of the grid is one high-lift propeller diameter, and these stations equate to $3 / 4$ of the propeller radius. Pressure coefficient data for the unblown and blown wing are shown in Figures $29 \mathrm{a}$ and $29 \mathrm{~b}$ for angles of attack $0^{\circ}$ and $4^{\circ}$, respectively. There is a much higher lift and a higher negative pressure peak computed at Station 1 (blade up) as compared to Station 2 (blade down) for the blown wing (power) case. For the $\alpha=4^{\circ}$, at Station 2, even though the negative pressure peaks are of the same magnitude between the blown and unblown case, the blown case has increased lift due to the higher velocities on the upper surface. The unblown wing (no power) has nearly the same pressure distribution at Stations 1 and 2 as expected.

\section{Investigating Propeller Diameter to Wing Chord on Blown High-Lift Performance}

Another unknown in the process of designing the DEP high-lift system is the optimum ratio of the diameter of the high-lift propellers to the wing chord. The result of this determines the number of motors/propellers/nacelles that are needed to span the area desired for blown high lift. This design parameter also has a large influence on the cost of the DEP system and on the impacts of the nacelles on unblown wing cruise and high-lift performance. In addition, to minimize cruise drag, the high-lift propellers need to fold during cruise. The larger ratio of the high-lift propeller diameter to the wing chord, the farther the high-lift nacelles have to extend forward in front of the wing to be able to fold. Furthermore, the propeller disk plane is moved farther forward of the wing. To help quantify the sensitivity of blown high-lift performance to this ratio, a CFD study was conducted by varying the chord of an airfoil downstream of a fixed geometry high-lift propeller. This study was conducted with a geometry similar to the previous study, an airfoil extended across an infinite-span grid that was behind a single high-lift propeller and 
nacelle. Since the objective of this study was primarily to find the propeller diameter to wing chord ratio that optimizes the blowing effect on the wing, a cruise airfoil was chosen for the airfoil geometry. If a flapped section had been chosen, there would also have been strong Reynolds number effects on the high-lift performance, since the $\mathrm{c}=0.5$ airfoil has 0.25 times the Reynolds number of the $\mathrm{c}=2.0$ geometry.

The infinite-span study geometry was the HEIST cruise wing airfoil behind a high-lift propeller and nacelle. The study was conducted with FUN3D using the SARCQCR turbulence model, to examine the sensitivities of the propeller diameter to chord length. Three tetrahedral meshes were generated with the GridTool and VGRID software, using nondimensional reference chords of 0.5, 1.0, and 2.0, with a reference span of 0.8548 , as described previously in Section IV, Grid Generation, Computational Scheme, and Convergence. The reference span of 0.8548 represents the nondimensional distance between nacelles of the HEIST wing, and is also equivalent to the propeller diameter. The airfoil section has an incidence of $3.5^{\circ}$.

The analyses were conducted at $M_{\infty}=0.0962, \alpha=0^{\circ}$, and with $R e=0.5$ million for $c_{r e f}=0.5, R e=1$ million for $c_{r e f}=1.0$, and $R e=2$ million for $c_{r e f}=2.0$. The inputs for the actuator disk model were thrust $=44.74 \mathrm{lb}$, and torque $=14.23 \mathrm{lb}$-ft for power conditions of $16.7 \mathrm{hp} / \mathrm{prop}$ at $6147 \mathrm{RPM}$. Figure 30 shows a side view of each wing section with nacelle, along with an oblique view of the upper surface pressure coefficient contours and Mach contours on planes through the wing section. Pressure coefficient distributions were taken at two spanwise stations corresponding to $1 / 8^{\text {th }}$ and $7 / 8^{\text {th }}$ of the propeller diameter: Station 1 (blade up) and Station 2 (blade down) are shown in Figure 31. Note the width of the grid is one high-lift propeller diameter, and these stations equate $3 / 4$ of the propeller radius. The corresponding pressure coefficient data at Stations 1 and 2 for the base chord (1.0), base chord $* 0.5$, and base chord*2.0 are shown in Figure 32 for the unblown and blown HEIST cruise wing. The pressure coefficient distributions are fairly similar for the unblown wing (Figs. 32a and 32c). The $\mathrm{c}=0.5$ case has a larger decrement in lift, due to the larger proportion of the nacelle to the wing chord. For the blown wing case, Station 1 (blade up) peak pressure coefficients are much higher negative values than at Station 2 (blade down) (compare Figs. $32 \mathrm{~b}$ and $32 \mathrm{~d}$ ).

The station 1 negative pressure peaks and overall lift increase for the blown wing as the chord is reduced (Fig. 32b). For station 2 (Fig. 32d) the opposite trend occurs and the lift increases with increasing chord. The impacts of the swirl due to the downward blade cause negative lift on the airfoil section. For the $\mathrm{c}=0.5$ case, there is a pronounced negative pressure peak on the lower surface and negative lift on the forward $20 \%$ of the airfoil chord. Also, the lift that is carried between $20 \%$ chord and $60 \%$ chord is significantly reduced compared to the $\mathrm{c}=$ 1.0 and $\mathrm{c}=2.0$ cases. The $\mathrm{c}=2.0$ case only has a small region of negative lift in the first few percent of the leading edge. These effects can be seen in the integrated $C_{L}$ results that are in Table 6. The highest effective blown $C_{L}$ is for the $\mathrm{c}=1.0$ case $\left(C_{L}=1.79\right)$. The $\mathrm{c}=2.0$ case has a lift coefficient of 1.69 , and the $\mathrm{c}=0.5$ case is even lower at $C_{L}=$ 1.52. Examining the unblown lift coefficients, they are not constant due to the impacts of the relative size of the high-lift nacelle on the wing lift. From test data, the GAW-1 airfoil at $\alpha=3.5^{\circ}$ (incidence $=3.5^{\circ}$ ) has a $c_{l}$ of 0.780 , for $R e=2.1 \times 10^{6}$. There is a large lift decrement for the $\mathrm{c}=0.5$ case due to the large nacelle and the lower Reynolds number, $R e=0.5 \times 10^{6}$. The lift decrement from the larger nacelle actually limits the lift augmentation for the smaller chords. Based upon these results a propeller diameter to wing chord ratio on the order of 1.0 seems to yield the overall best lift benefit to the blown wing. This also seems to be a practical compromise between more propellers and motors versus low wing chord Reynolds numbers and long extended nacelles. The propeller diameter to chord ratio on the X-57 Maxwell varies from 1.0 at the outboard location to 0.79 at the inboard location.

\section{Conclusions}

A computational and design study on an airfoil and high-lift flap for the X-57 Maxwell Distributed Electric Propulsion (DEP) test bed aircraft was conducted. To meet the requirements of a low drag airfoil at a cruise with a high $c_{l, \text { max }}$, the GNEW5BP93B airfoil was designed. The minimum drag coefficient was $c_{d}=0.0053$ at $c_{l}=0.90$ and $R e=2.35 \times 10^{6}$. Laminar flow extends to $69 \%$ chord on the upper surface and $62 \%$ chord on the lower surface of the GNEW5BP93B airfoil. With fully turbulent flow, the drag increases to $c_{d}=0.0120$. The predicted maximum lift with turbulent flow is a $c_{l, \max }$ of 1.95 , at $\alpha=19^{\circ}$. The airfoil is characterized by relatively flat pressure gradient regions on both surfaces at $\alpha=0^{\circ}$, and aft camber to get extra lift out of the lower surface concave region. A $25 \%$ chord slotted flap was designed for a $30^{\circ}$ flap deflection. MSES and USM3D calculations obtained a maximum $c_{l}$ between 2.41 and 3.23 for the $30^{\circ}$ flap deflection cases analyzed at $R e=1.0 \times 10^{6}$ (and $R e=1.0 \times 10^{6}$ ) based on reference chord of 1.0. An infinite-span powered high-lift study was conducted on a GAW-1 constant chord $40^{\circ}$ flapped airfoil section with FUN3D to quantify the airfoil lift increment that can be expected from a DEP system. The blown wing using the DEP system with $16.7 \mathrm{hp} /$ propeller increases the maximum $C_{L}$ from 3.45 to 6.43 , which is an effective $q$ ratio of 1.86. This indicates that if the unblown high-lift flapped airfoil of the X-57 airplane 
achieves a $c_{l, \max }$ of 2.78, then the high-lift augmentation blowing could yield a sectional lift coefficient of approximately 4.95 at $c_{l, \max }$ Finally, a computational study was conducted with FUN3D on an infinite-span constant chord GAW-1 cruise airfoil to determine the impact of high-lift propeller diameter to wing chord ratio on the lift increment of the DEP system. A constant diameter propeller and nacelle size were used in the study. Three CFD grids were made with airfoil chords of $0.5 \mathrm{c}, 1.0 \mathrm{c}$, and $2.0 \mathrm{c}$. Results of the study indicated that the blown to unblown $C_{L}$ ratio increased as the chord was decreased, but the increase in relative size of the high-lift nacelle to the wing impacted wing lift performance. The study indicated that a propeller diameter to wing chord ratio of 1.0 gives the overall best maximum lift on the wing with the DEP system.

\section{Acknowledgements}

The authors would like to thank Mr. Michael Wiese and Ms. Norma Farr with Craig Technologies, working in the NASA Geometry Lab, for providing the HEIST grids in support of the CFD analyses conducted under the SCEPTOR project. We would also like to thank Mr. Richard Campbell for providing the USM3D 2-D grids and other CFD support as part of this effort.

\section{References}

1 Borer, Patterson, Viken, Moore, Clarke, Redifer, Christie, Stoll, Dubois, Bevirt, Gibson, Foster, Osterkamp, "Design and Performance of the NASA SCEPTOR Distributed Electric Propulsion Flight Demonstrator," Aviation Forum in Washington D. C., AIAA 2016-3920, 13-17 June 2016.

2 Stoll, A. M., "Comparison of CFD and Experimental Results of the LEAPTech Distributed Electric Propulsion Blown Wing," AIAA 2015-3188, 22-26 June 2015.

3 Wentz, W.H., Jr. and Setharam, H. C., "Development of a Fowler Flap System for a High Performance General Aviation Airfoil,” NASA Contractor Report CR-2443, December 1974.

4 McGhee, Robert J. and Beasley, William D., "Effects of Thickness on the Aerodynamic Characteristics of an Initial LowSpeed Family of Airfoils for General Aviation Applications," NASA TMX X-72843, June 1976.

5 Wentz, W.H., Jr. and Setharam, H. C., Fiscko, K. A., "Force and Pressure Tests of the GA(W)-1 Airfoil with a 20\% Aileron and Pressure Tests with 30\% Fowler Flap," NASA CR-2833, June 1977.

6 Giles, Michael B, and Drela, Mark, “Two-Dimensional Transonic Aerodynamic Design Method,” AIAA Journal Vol. 25 No 9. September 1987.

7 Drela, Mark; "Two-Dimensional Transonic Aerodynamic Design and Analysis Using the Euler Equations," Massachusetts Institute of Technology, Gas Turbine Laboratory Rept. 186, Feb.1986.

8 Campbell, Richard L. and Smith, Leigh A., “A Hybrid Algorithm for Transonic Airfoil and Wing Design,” AIAA-87-2552, 1987.

9 Frink, N. T., “Tetrahedral Unstructured Navier-Stokes Method for Turbulent Flow,” AIAA Journal, Vol. 36, No. 11, Nov. 1998, pp. 1975-1982.

10 Frink, N. T., Pirzadeh, S. Z., Parikh, P. C., Pandya, M. J., and Bhat, M. K., "The NASA Tetrahedral Unstructured Software System," The Aeronautical Journal, Vol. 104, No. 1040, October 2000, pp. 491-499.

11 Roe, P., "Approximate Riemann Solvers, Parameter Vectors, and Difference Schemes," J. of Comp. Phys., vol. 43, pp. 357372, 1981.

12 Spalart, P. R., "Strategies for Turbulence Modelling and Simulation. International Journal of Heat and Fluid Flow," Vol. 21, 2000, pp. 252-263.

13 Shur, M. L., Strelets, M. K., Travin, A. K., Spalart, P. R., “Turbulence Modeling in Rotating and Curved Channels: Assessing the Spalart-Shur Correction,” AIAA Journal Vol. 38, No. 5, 2000, pp. 784-792.

14 Menter, F. R., “Two-Equation Eddy-Viscosity Turbulence Models for Engineering Applications,” AIAA Journal, Vol. 32 , No. 8, August 1994, pp. 1598-1605. 
Denver, CO

15 Nayani, Sudheer N., and Campbell, Richard L., "Evaluation of Grid Modification for On- and Off-Track Sonic Boom Analysis," AIAA 2013-0798, January 2013.

16 “2 $2^{\text {nd }}$ AIAA CFD High Lift Prediction Workshop Gridding Guidelines," http://hiliftpw.larc.nasa.gov, https://hiliftpw.larc.nasa.gov/Workshop2/GriddingGuidelines-HiLiftPW2-v2.pdf, March 2013.

17 Wentz, W.H., Jr., "Wind Tunnel Test of the GA(W)-2 Airfoil with 20\% Aileron, 25\% Slotted Flap, 30\% Fowler Flap, 10\% Slot-Lip Spoiler,” NASA Contractor Report CR-145139, August 1976.

18 Biedron, R. T., Carlson, J. R., Derlaga, J. M., Gnoffo, P. A., Hammond, D. P., Jones, W. T., Kleb, B., Lee-Rausch, E. M., Nielsen, E. J., Park, M. A., Rumsey, C. L., Thomas, J. L., and Wood, W. A., "FUN3D Manual: 13.0," NASA TM-2016219330.

19 Drela, M., and Youngren, H., “XROTOR Download Page," http://web.mit.edu/drela/Public/web/xrotor/, accessed 6 May 2014.

Table 1. Comparison of Wing Sizing Parameters of the Tecnam P2006T and X-57/SCEPTOR.

\begin{tabular}{|l|l|l|}
\hline & Tecnam P2006T & X-57 / SCEPTOR \\
\hline Wing Loading $(W / S)-\mathrm{lbs} / \mathrm{ft}^{2}$ & 16.365 & 45 \\
\hline Wing Area $(S)-\mathrm{ft}^{2}$ & 158.88 & $66.67(0.42 *$ original Tecnam $)$ \\
\hline Aspect Ratio $(A R)$ & 8.8 & $15 \quad(1.7 *$ original Tecnam $)$ \\
\hline Cruise $C_{L}$ & 0.275 & $0.75(2.75 *$ original Tecnam $)$ \\
\hline
\end{tabular}

Table 2. Flap Deflection and Location Information for USM3D Study.

\begin{tabular}{|c|r|r|r|r|r|r|r|}
\hline $\begin{array}{c}\text { Grid } \\
\text { Name }\end{array}$ & \multicolumn{1}{|c|}{ Overlap/c } & $\begin{array}{c}\text { Gap/c } \\
\text { (minimum) }\end{array}$ & $\begin{array}{c}\text { Gap/c } \\
\text { (from trailing } \\
\text { edge) }\end{array}$ & $\begin{array}{c}\text { Flap } \\
\text { X-translation/c }\end{array}$ & $\begin{array}{c}\text { Flap } \\
\text { Y-translation/c }\end{array}$ & $\begin{array}{c}\text { Flap } \\
\text { X-rotation/c }\end{array}$ & $\begin{array}{c}\text { Flap } \\
\text { Y-rotation/ }\end{array}$ \\
\hline f30 & -0.005361 & 0.026557 & 0.026557 & 0.1283 & 0.0395 & 0.8125 & 0.038063 \\
\hline f30a & 0.009639 & 0.011723 & 0.011723 & 0.1133 & 0.0495 & 0.8125 & 0.038063 \\
\hline f40 & -0.013210 & 0.028251 & 0.028251 & & & 0.8175 & -0.166 \\
\hline f40a & 0.011451 & 0.014539 & 0.04539 & & & 0.811 & -0.130 \\
\hline
\end{tabular}

Table 3: Mesh Sizes for the f30, f30a, f40, and f40a Grids.

\begin{tabular}{|c|c|c|}
\hline Grids & $\begin{array}{c}\text { Flapped Airfoil } \\
\text { Deflection (deg) }\end{array}$ & Tetrahedral Cells \\
\hline f30 & 30 & 465,210 \\
\hline f30a & 30 & 451,656 \\
\hline f40 & 40 & 510,726 \\
\hline f40a & 40 & 515,535 \\
\hline
\end{tabular}


Table 4a. USM3D f30 Flapped Airfoil Solutions at $M_{\infty}=0.096, R e=1$ million.

\begin{tabular}{|c|c|c|c|c|}
\hline $\begin{array}{c}\text { Turbulence } \\
\text { Model }\end{array}$ & $\alpha$, deg & $\boldsymbol{c}_{\boldsymbol{l}}$ & $\boldsymbol{c}_{\boldsymbol{d}}$ & $\boldsymbol{c}_{\boldsymbol{m}}$ \\
\hline SA & 6 & 2.6620 & 0.06026 & -0.5077 \\
\hline SAQCR & 6 & 2.4750 & 0.06649 & -0.4625 \\
\hline SST & 6 & 2.4063 & 0.07313 & -0.4495 \\
\hline SA & 10 & 3.0648 & 0.06960 & -0.5091 \\
\hline SAQCR & 10 & & & -0.4578 \\
\hline SST & 10 & 2.8450 & 0.07628 & -0.5172 \\
\hline
\end{tabular}

Table 4b. USM3D f30a Flapped Airfoil Solutions at $M_{\infty}=0.096, R e=1$ million.

\begin{tabular}{|c|c|c|c|c|}
\hline $\begin{array}{c}\text { Turbulence } \\
\text { Model }\end{array}$ & $\begin{array}{c}\alpha, \\
\text { deg }\end{array}$ & $\boldsymbol{c}_{\boldsymbol{l}}$ & $\boldsymbol{c}_{\boldsymbol{d}}$ & $\boldsymbol{c}_{\boldsymbol{m}}$ \\
\hline SA & 6 & 3.0472 & 0.04831 & -0.5691 \\
\hline SAQCR & 6 & 2.9794 & 0.04993 & -0.5526 \\
\hline SST & 6 & 2.7779 & 0.06159 & -0.5069 \\
\hline SA & 10 & 3.2255 & 0.06364 & -0.5157 \\
\hline SAQCR & 10 & 3.1221 & 0.06766 & -0.4929 \\
\hline SST & 10 & 2.7776 & 0.08978 & -0.4256 \\
\hline
\end{tabular}

Table 4c. USM3D f40a Flapped Airfoil Solutions at $M_{\infty}=0.096, R e=1$ million.

\begin{tabular}{|c|c|c|c|c|}
\hline $\begin{array}{c}\text { Turbulence } \\
\text { Model }\end{array}$ & $\alpha$, deg & $\boldsymbol{c}_{\boldsymbol{l}}$ & $\boldsymbol{c}_{\boldsymbol{d}}$ & $\boldsymbol{c}_{\boldsymbol{m}}$ \\
\hline SA & 10 & 3.3543 & 0.08390 & -0.53395 \\
\hline SAQCR & 10 & 3.1915 & 0.09190 & -0.49922 \\
\hline SST & 10 & 2.7368 & 0.12441 & -0.41596 \\
\hline
\end{tabular}


Denver, CO

Table 5. Predicted $\mathrm{x} / \mathrm{c}$ Upper Surface Flap Separation Location for the f30, f30a, and f40a Geometries at $M_{\infty}$ $=0.096, R e=1$ million, and $\alpha=10^{\circ}$ with the SA, SAQCR, and SST Turbulence Models (USM3D code).

\begin{tabular}{|c|c|c|c|c|c|}
\hline Configuration & \multicolumn{3}{|c|}{$\begin{array}{c}\text { Flap Element } \\
\text { (x/c upper surface separation location) }\end{array}$} & \multicolumn{2}{c|}{$\begin{array}{c}\text { Flap Element } \\
\text { (x/c upper surface geometry) }\end{array}$} \\
\hline & SA & SAQCR & SST & Leading Edge & Trailing Edge \\
\hline $\mathrm{f} 30$ & 0.977 & 0.953 & 1.089 & 0.880 & 1.089 \\
\hline $\mathrm{f} 30 \mathrm{a}$ & 1.073 & 1.073 & 1.073 & 0.865 & 1.074 \\
\hline $\mathrm{f} 40 \mathrm{a}$ & 1.045 & 1.044 & 1.045 & 0.864 & 1.046 \\
\hline
\end{tabular}

Table 6. Lift Comparison of the DEP High-Lift Augmentation with Variation of Chord.

\begin{tabular}{|l|l|l|l|}
\hline Chord ratio & $C_{L}$ (unblown) & $C_{L}$ (blown) & $C_{L}$ ratio - blown/unblown \\
\hline 0.5 & .532 & 1.52 & 2.857 \\
\hline 1.0 & .742 & 1.79 & 2.412 \\
\hline 2.0 & .801 & 1.69 & 2.110 \\
\hline
\end{tabular}

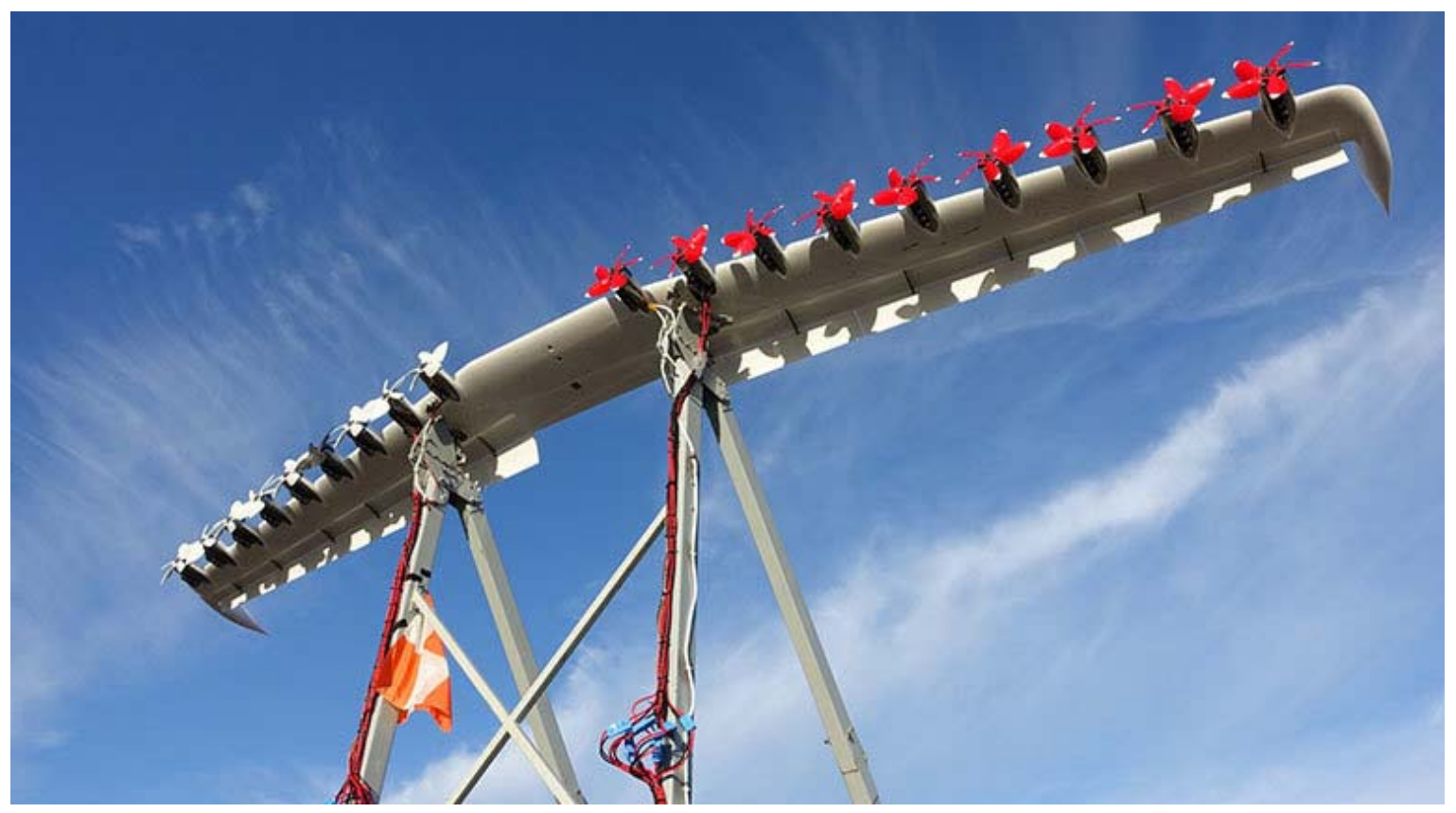

Figure 1. The DEP wing tested at NASA Armstrong on the Hybrid-Electric Integrated Systems Testbed (HEIST) truck. (NASA photograph) 


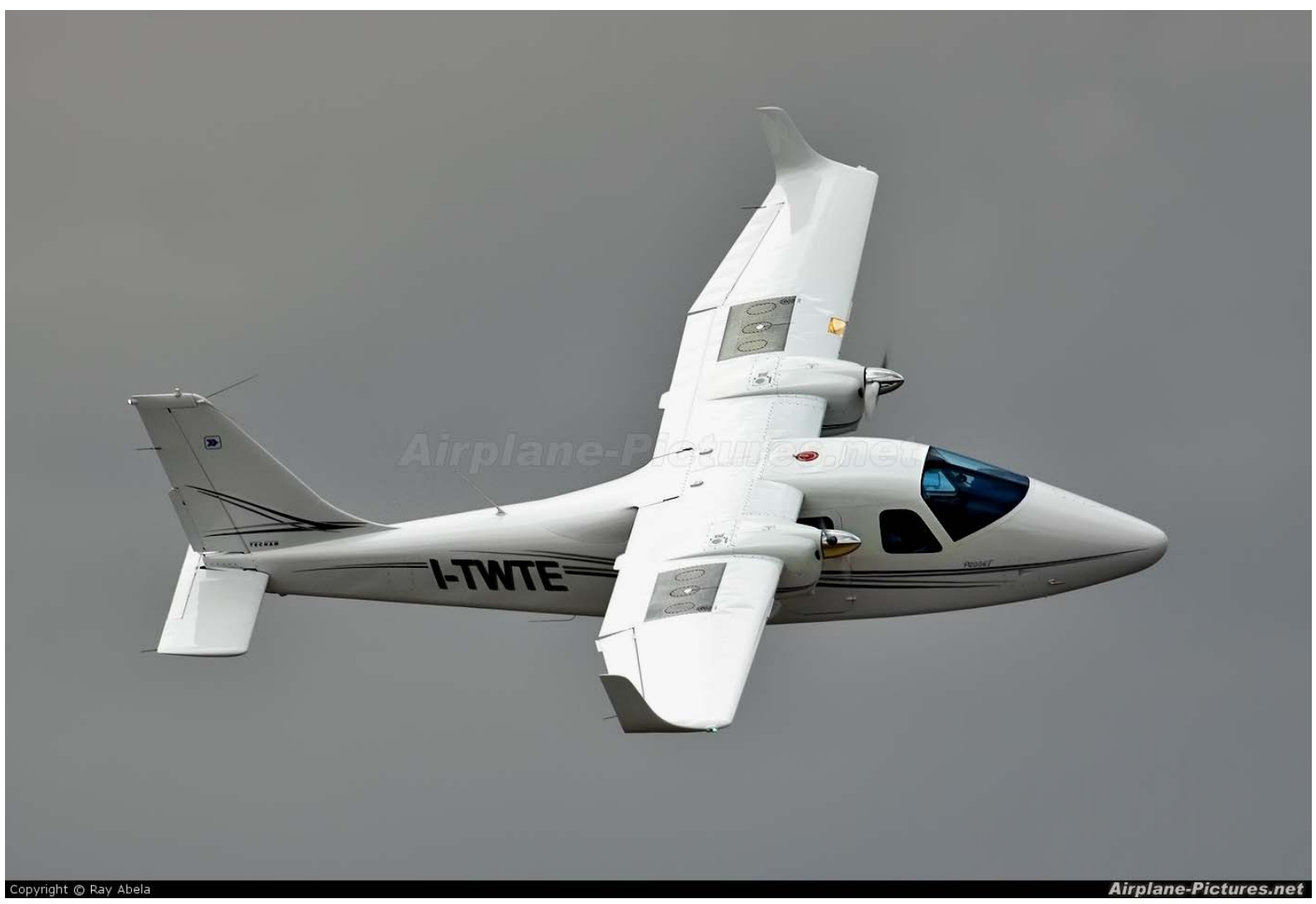

Figure 2. The original Tecnam P2006T aircraft.

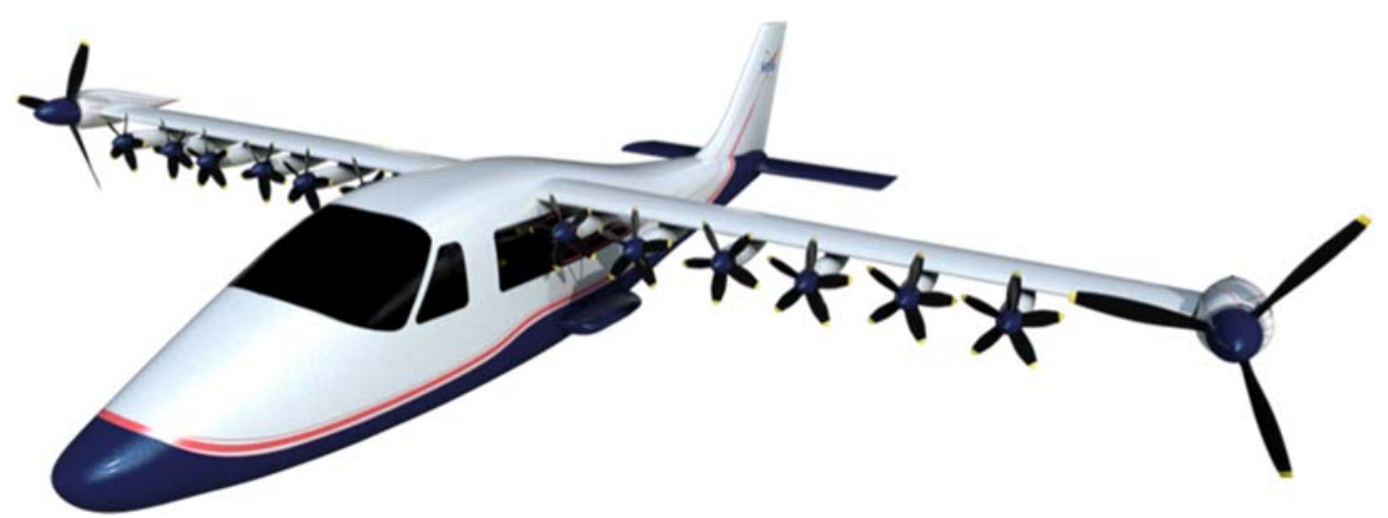

Figure 3. The X-57 Maxwell DEP aircraft. The Tecnam P2006T fuselage and tail with the DEP wing system that includes the wingtip propulsors and the DEP high-lift motors. 
Denver, CO

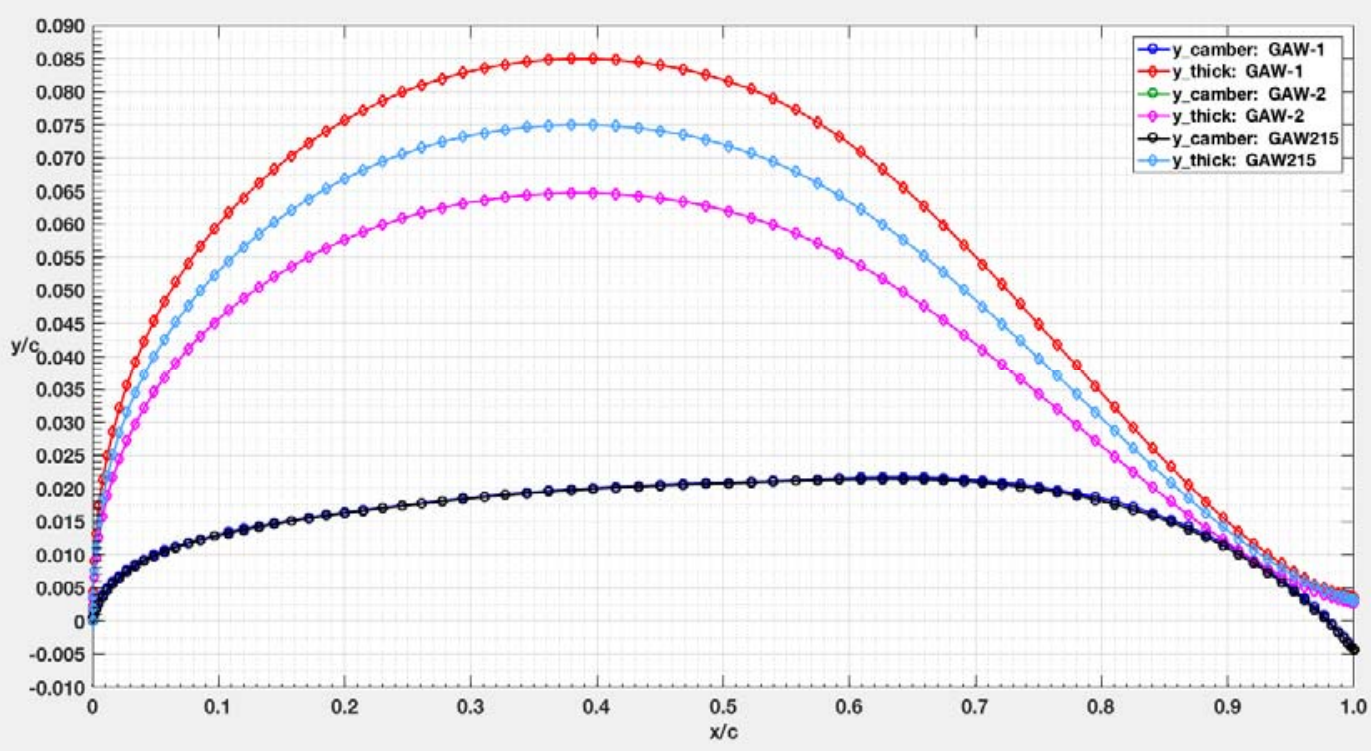

Figure 4. Airfoil thickness and camber distribution of the GAW-1, GAW-2, and GAW215 airfoils.

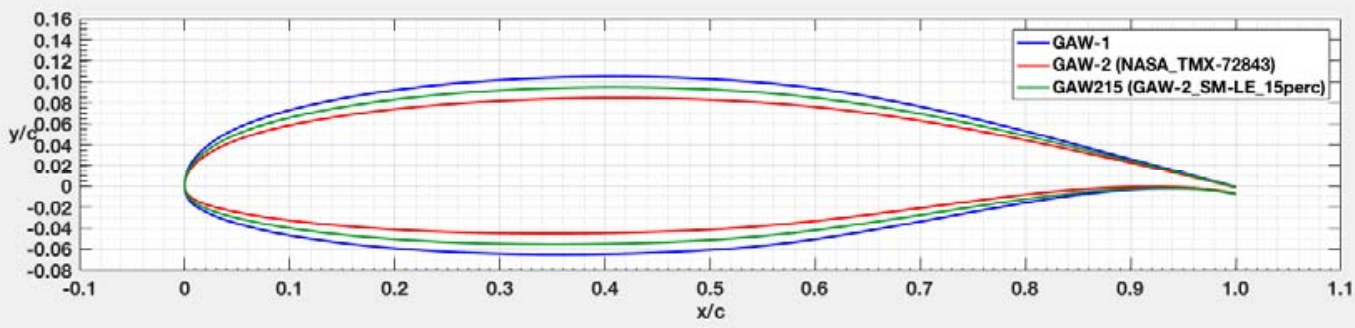

Figure 5. Airfoil coordinate comparison of the GAW-1, GAW-2, and GAW215 airfoils. 
Denver, CO

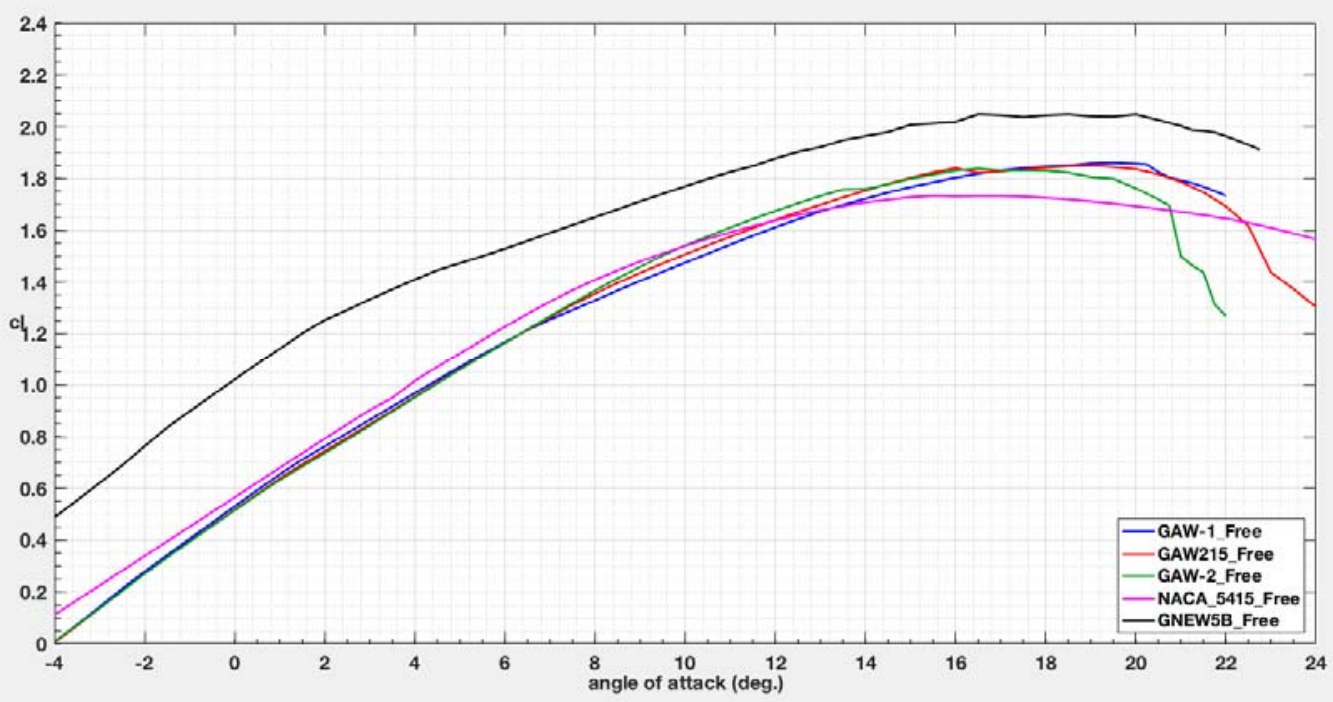

Figure 6a. Section lift airfoil comparison, free transition $\left(M_{\infty}=0.233, R e=2.35\right.$ million, Ncrit $\left.=9\right)$.

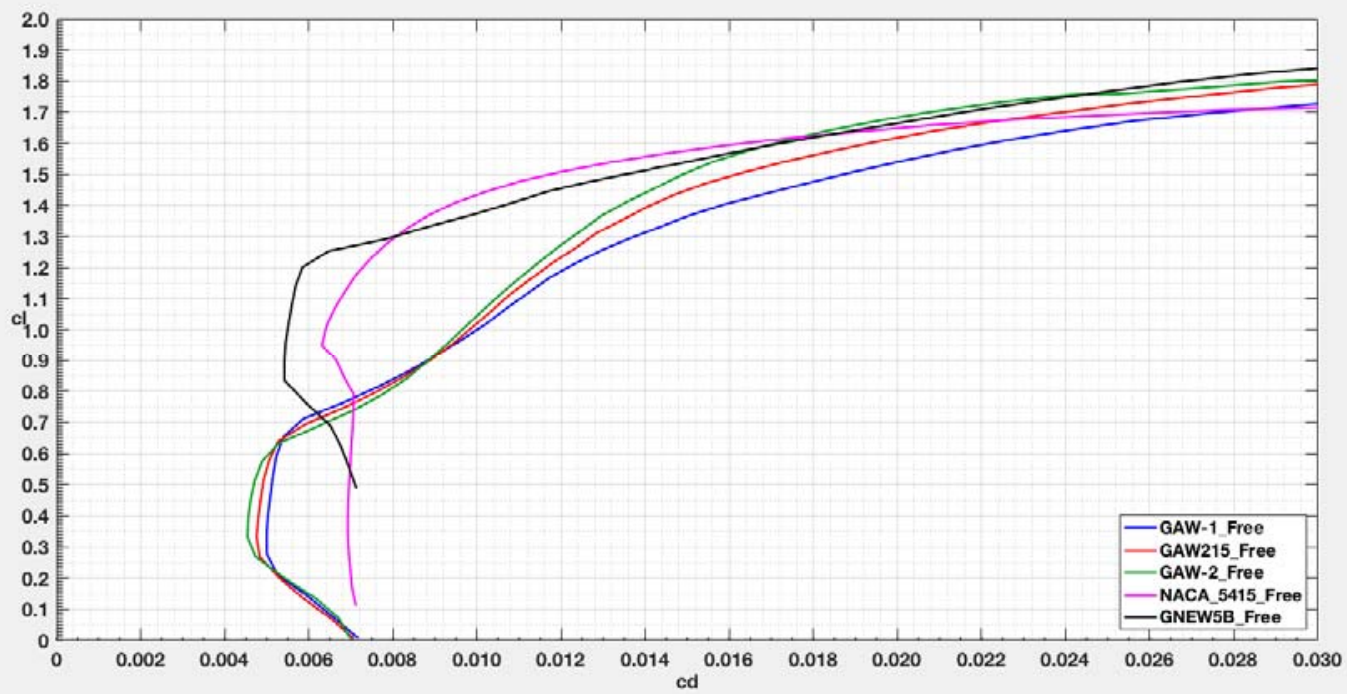

Figure 6b. Section lift-to-drag airfoil comparison, free transition $\left(M_{\infty}=0.233, R e=2.35\right.$ million, Ncrit $\left.=9\right)$. 
Denver, CO

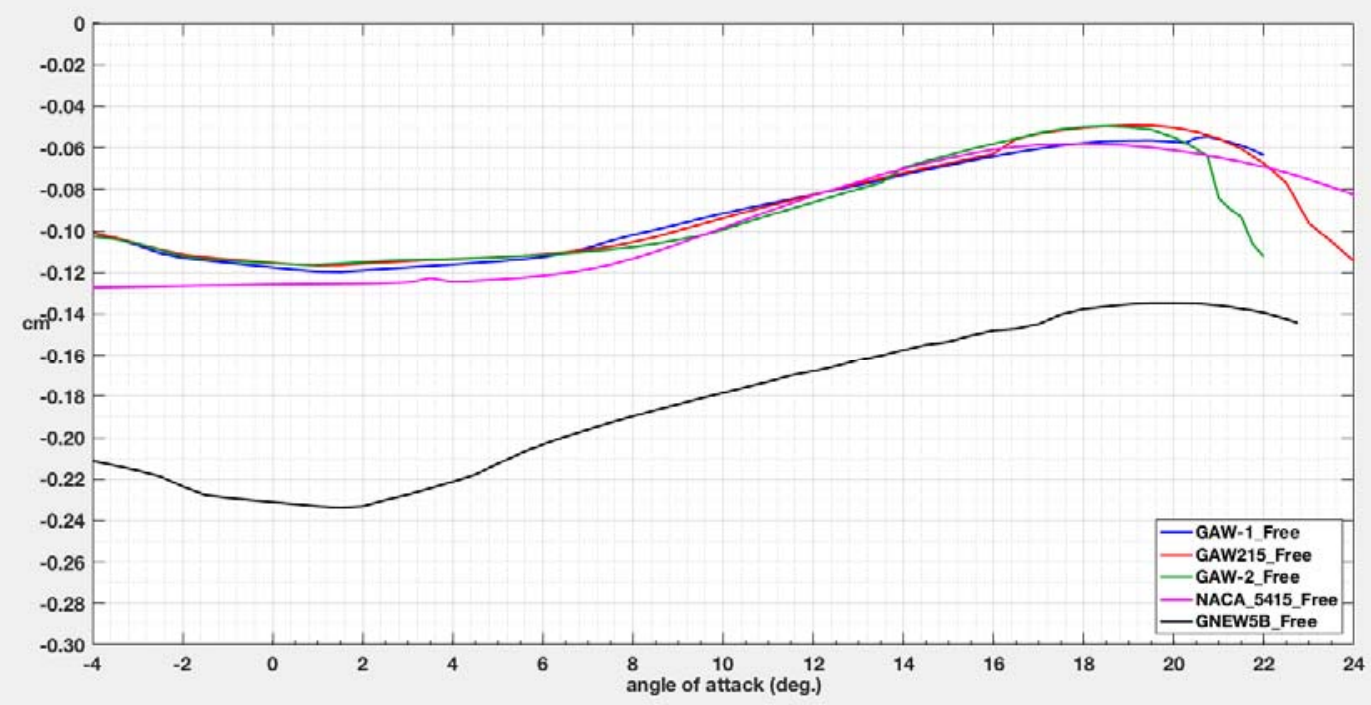

Figure 6c. Section pitching moment airfoil comparison, free transition $\left(M_{\infty}=0.233, R e=2.35\right.$ million, Ncrit $=$ 9).

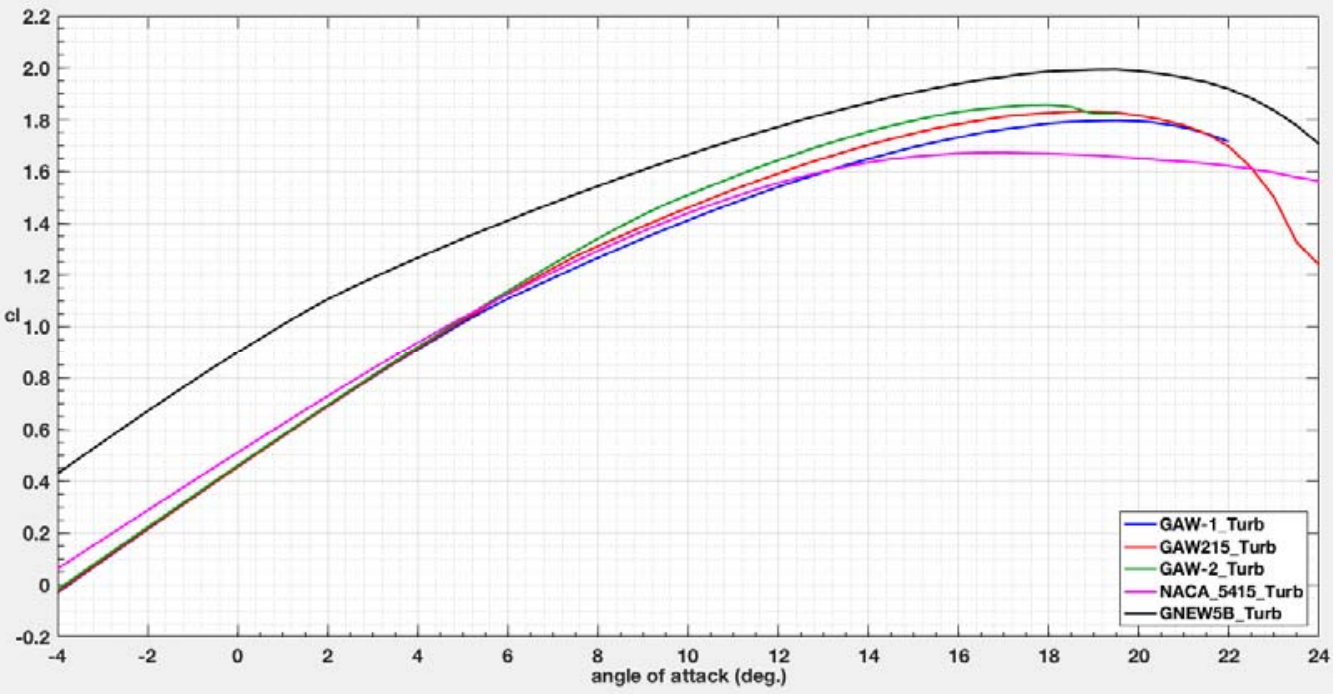

Figure 7a. Section lift airfoil comparison, fully turbulent $\left(M_{\infty}=0.233, R e=2.35\right.$ million, Ncrit $\left.=9\right)$. 
Denver, CO

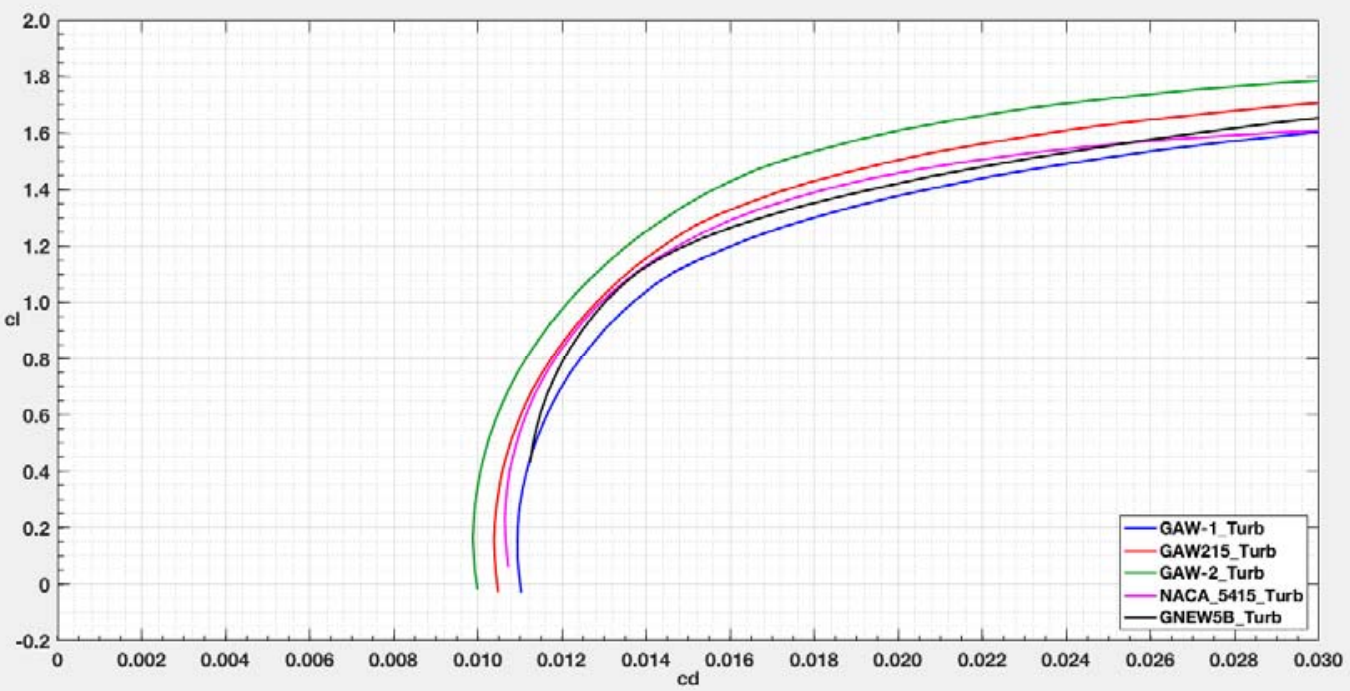

Figure 7b. Section drag airfoil comparison, fully turbulent $\left(M_{\infty}=0.233, R e=2.35\right.$ million, Ncrit $\left.=9\right)$.

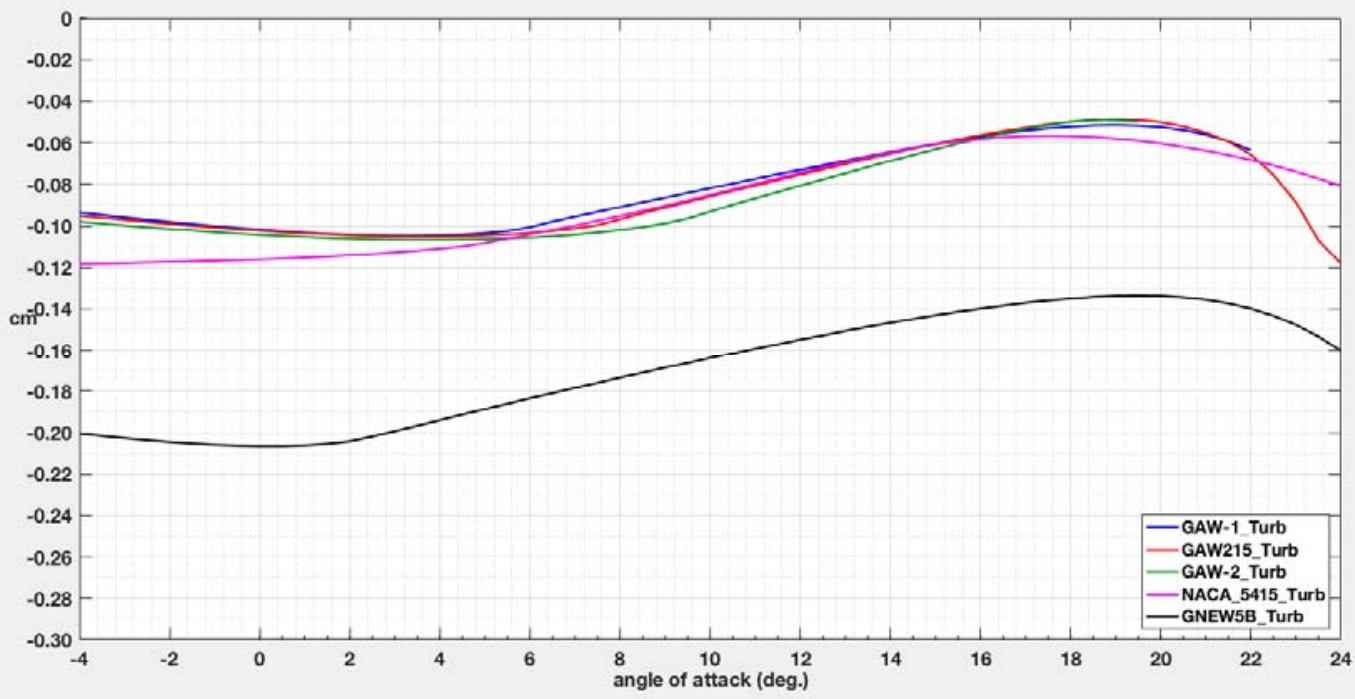

Figure 7c. Section pitching moment airfoil comparison, fully turbulent $\left(M_{\infty}=\mathbf{0 . 2 3 3}, \mathbf{R e}=2.35\right.$ million, Ncrit =9). 
Denver, CO
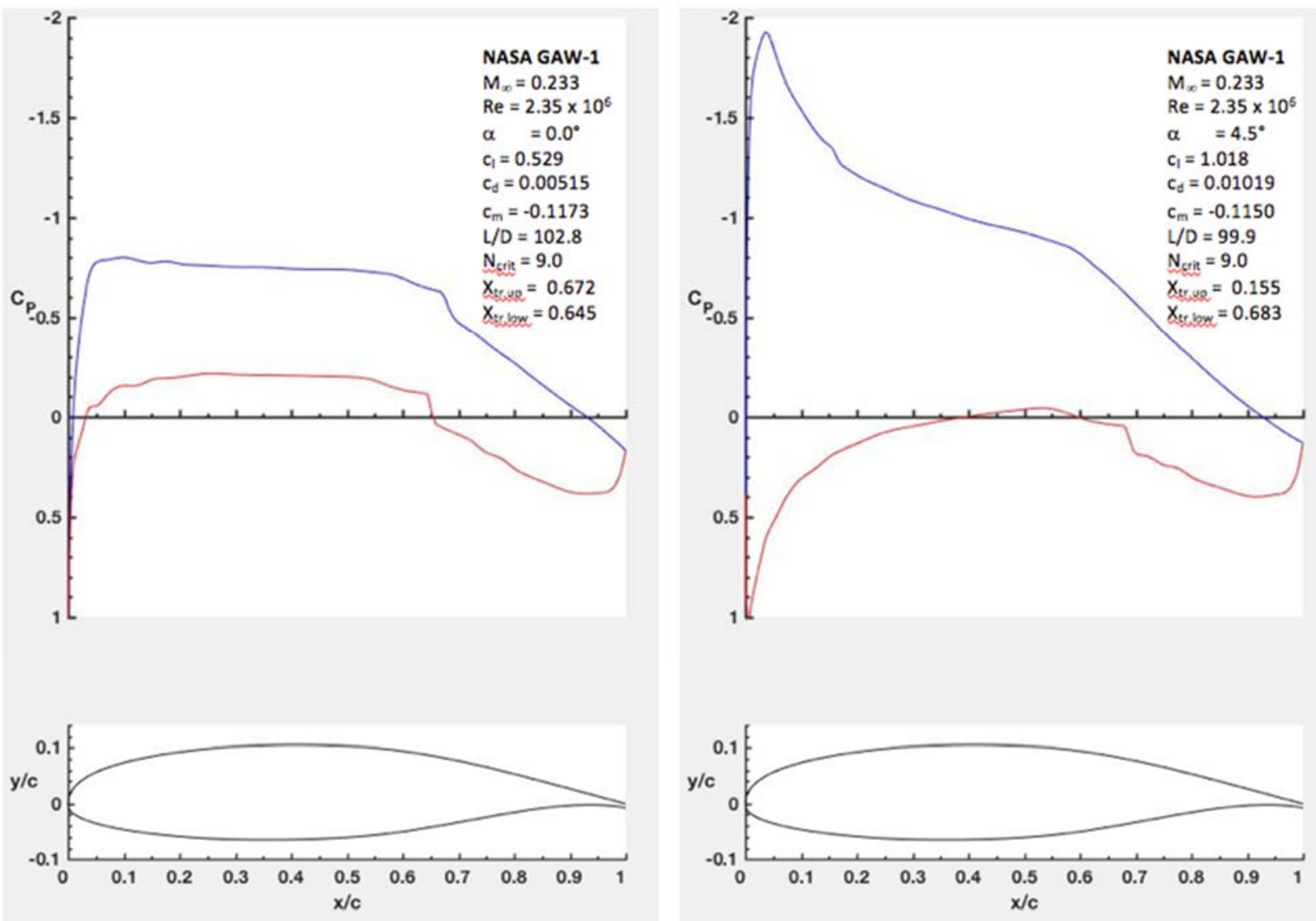

Figure 8a

Figure $8 b$

Figure 8. Pressure distribution for the GAW-1 airfoil at $\alpha=0.0^{\circ}$ (left) and $4.5^{\circ}$ (right), $M_{\infty}=0.233, R e=2.35$ million, and Ncrit $=9$. 
Denver, CO
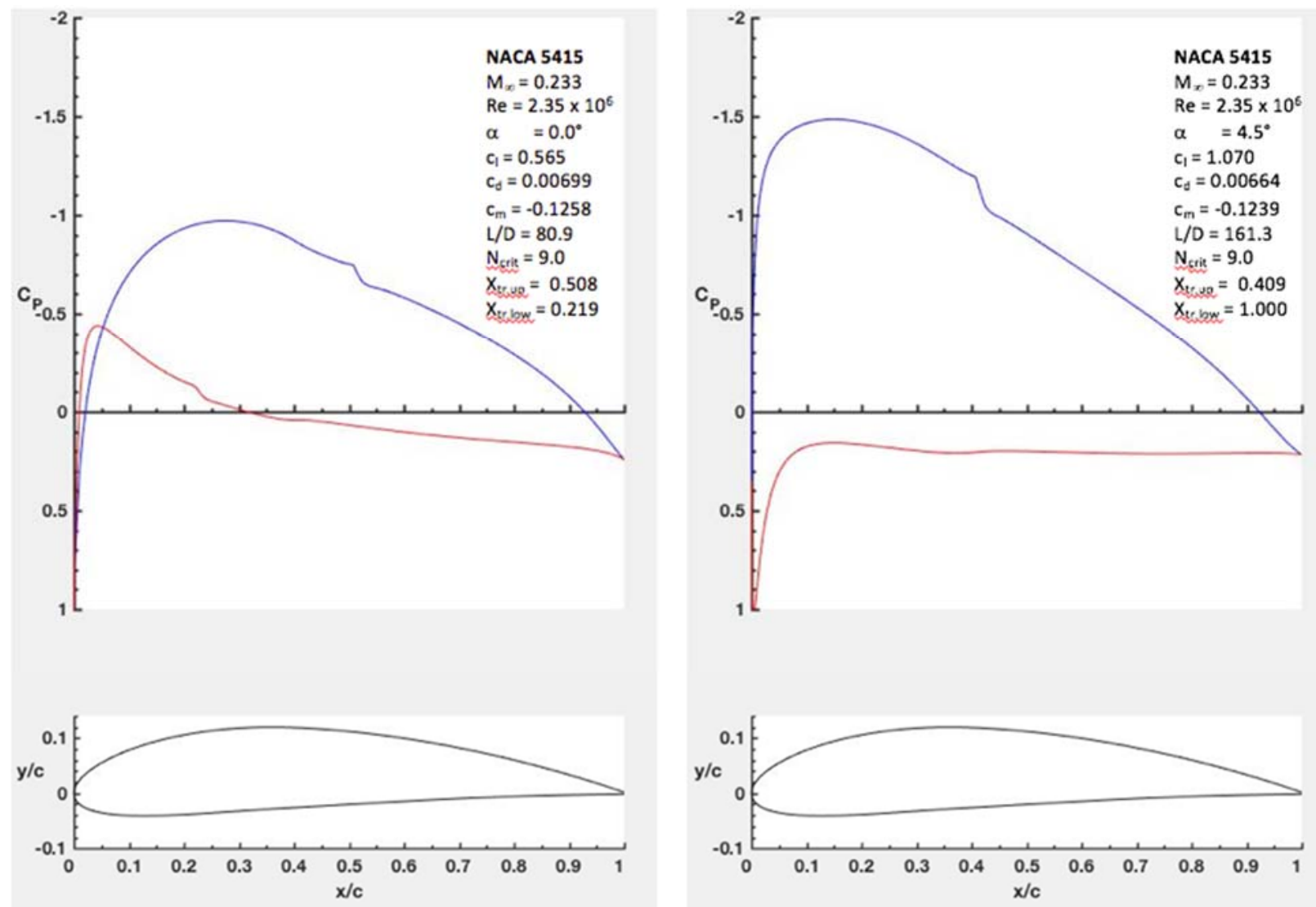

Figure 9a

Figure 9b

Figure 9. Pressure distribution for the NACA 5415 airfoil at $\alpha=0.0^{\circ}$ (left) and $4.0^{\circ}$ (right), $M_{\infty}=0.233, \operatorname{Re}=$ 2.35 million, Ncrit $=9$. 
Denver, CO

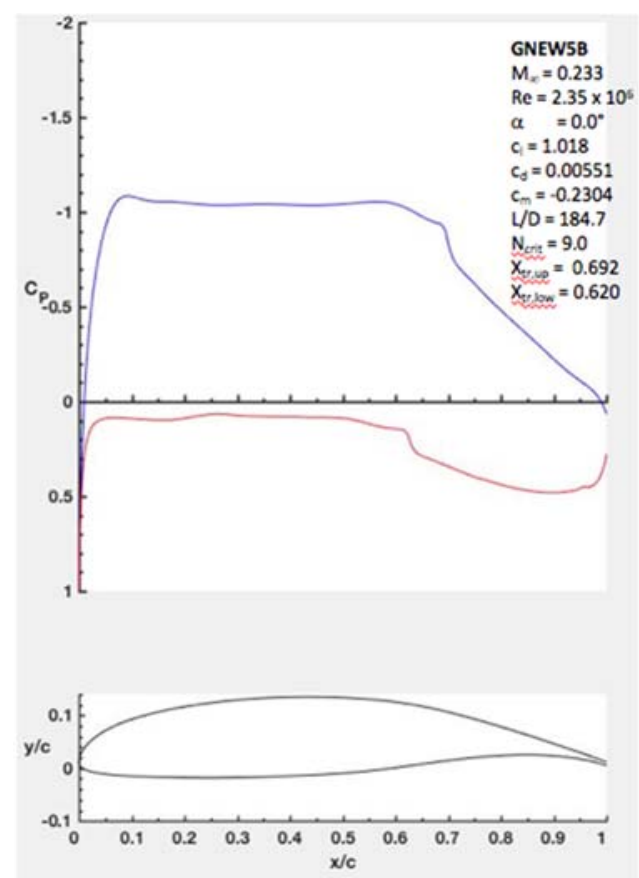

Figure 10. Pressure distribution for the GNEW5B airfoil at $\alpha=0.0^{\circ}, M_{\infty}=0.233, \operatorname{Re}=2.35$ million, Ncrit $=9$.

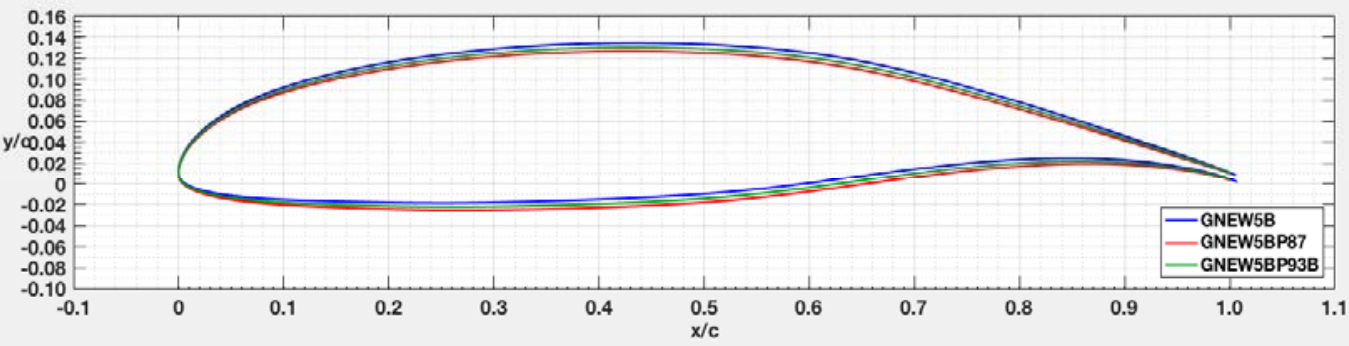

Figure 11. GNEW5BP87 and GNEW5BP93 airfoil scaled from camber line of the GNEW5B airfoil. 
Denver, CO

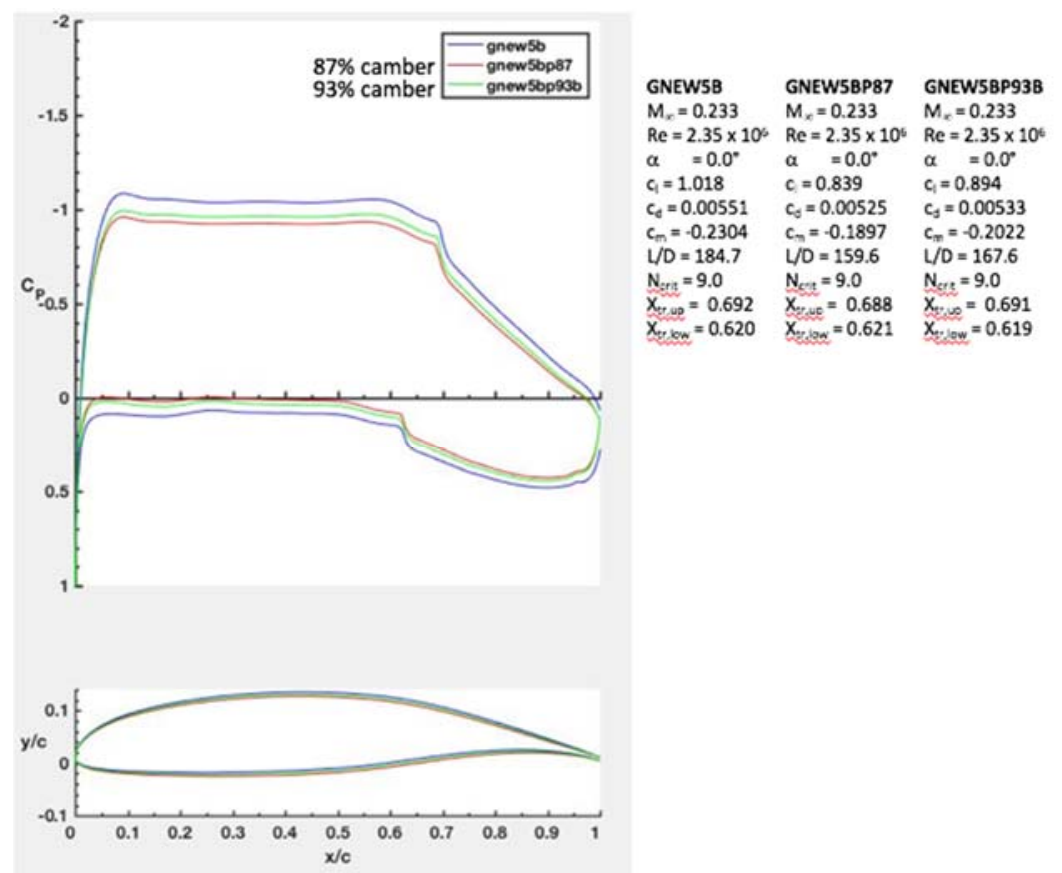

Figure 12. GNEW5BP87 and GNEW5BP93B airfoils with $87 \%$ and $93 \%$ scaled camber line from the GNEW5B airfoil $\left(\alpha=0.0^{\circ}, M_{\infty}=0.233, R e=2.35\right.$ million, Ncrit $\left.=9\right)$.

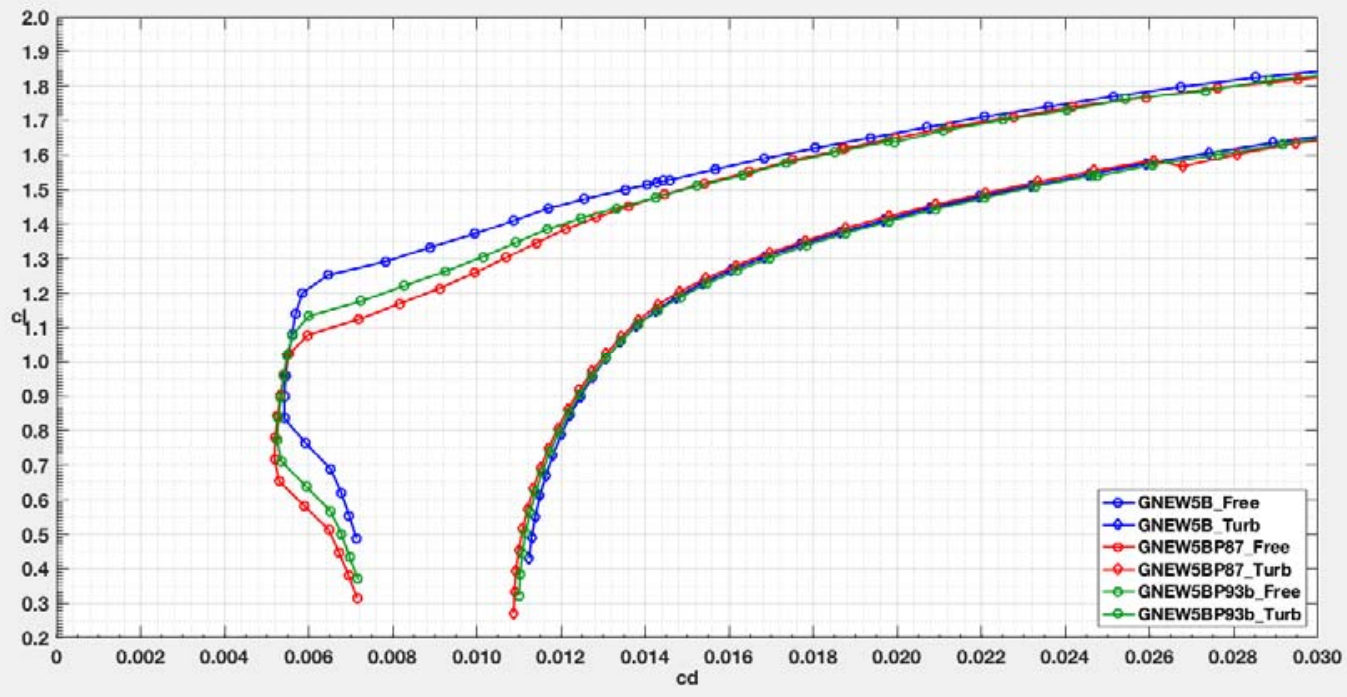

Figure 13. Drag comparison of the scaled camber line airfoils (GNEW5BP87 and GNEW5BP93B) from the GNEW5B airfoil. 
Denver, CO

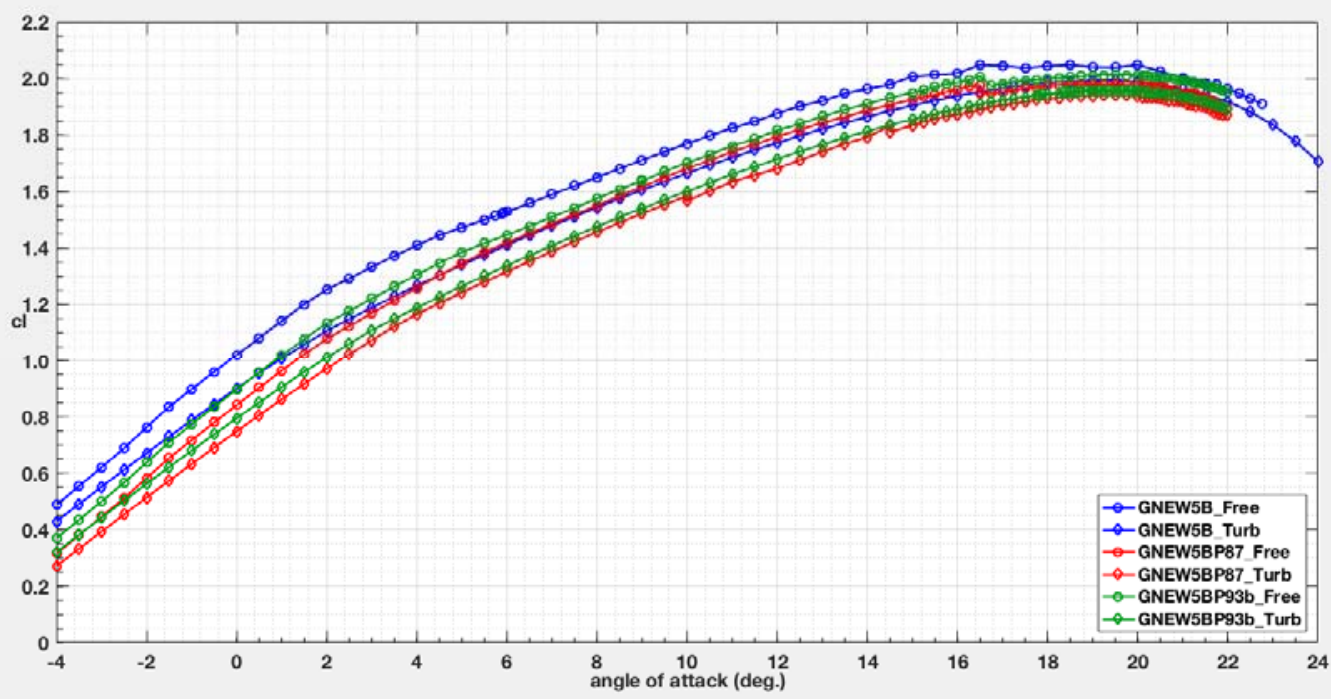

Figure 14. Lift comparison of the scaled camber line airfoils (GNEW5BP87 and GNEW5BP93B) to the GNEW5B airfoil.

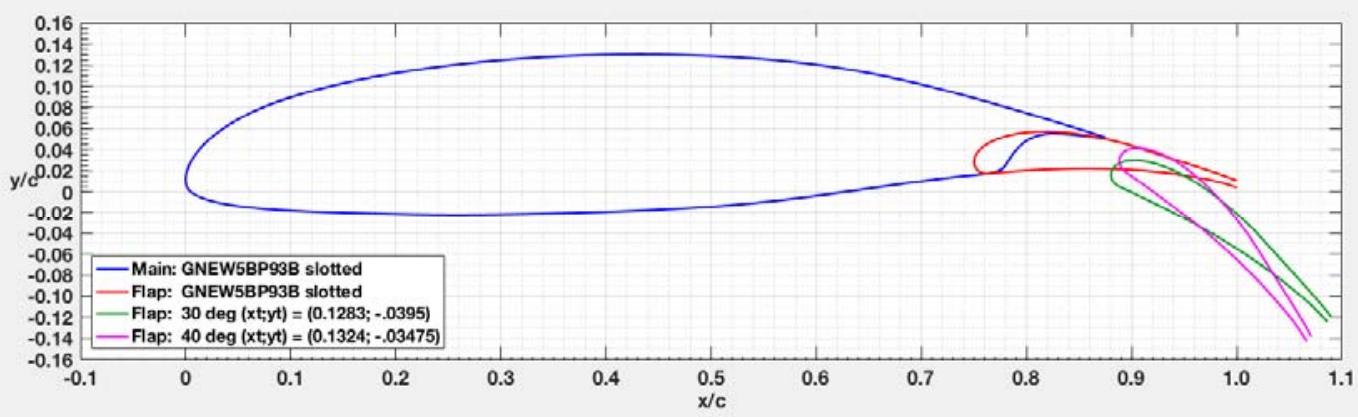

Figure 15. Coordinates of the GNEW5BP93B airfoil with $25 \%$ chord slotted flap deflected $30^{\circ}$ and $40^{\circ}$. 
Denver, CO

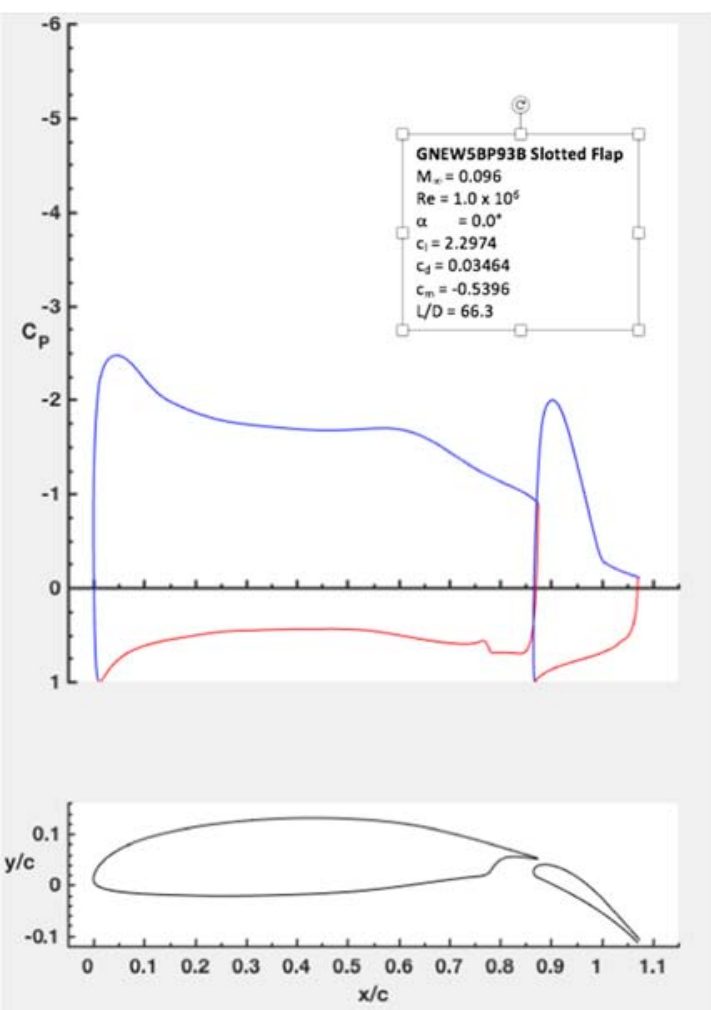

Figure 16a. Pressure distribution of the GNEW5BP93B airfoil with $25 \%$ chord slotted flap deflected $30^{\circ}(\alpha=$ $0^{\circ}, M_{\infty}=0.096, R e=1.0$ million, Ncrit $=9$ ). 
Denver, CO

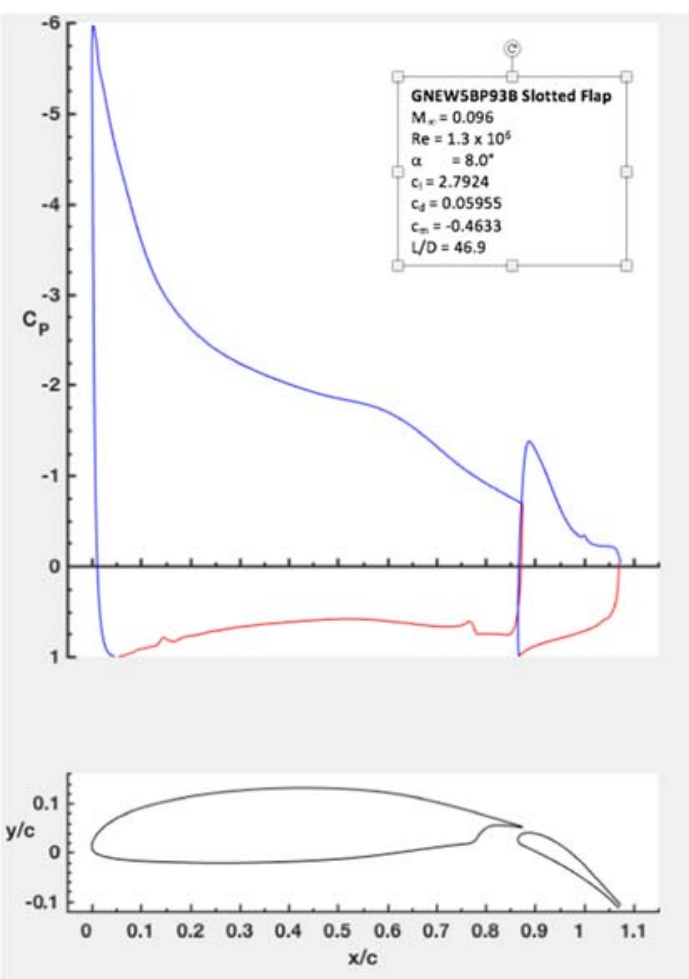

Figure 16b. Pressure distribution of the GNEW5BP93B with $25 \%$ chord slotted flap deflected $30^{\circ}\left(\alpha=10^{\circ}\right.$, $M_{\infty}=0.096, R e=1.3$ million, Ncrit $=9$ ).

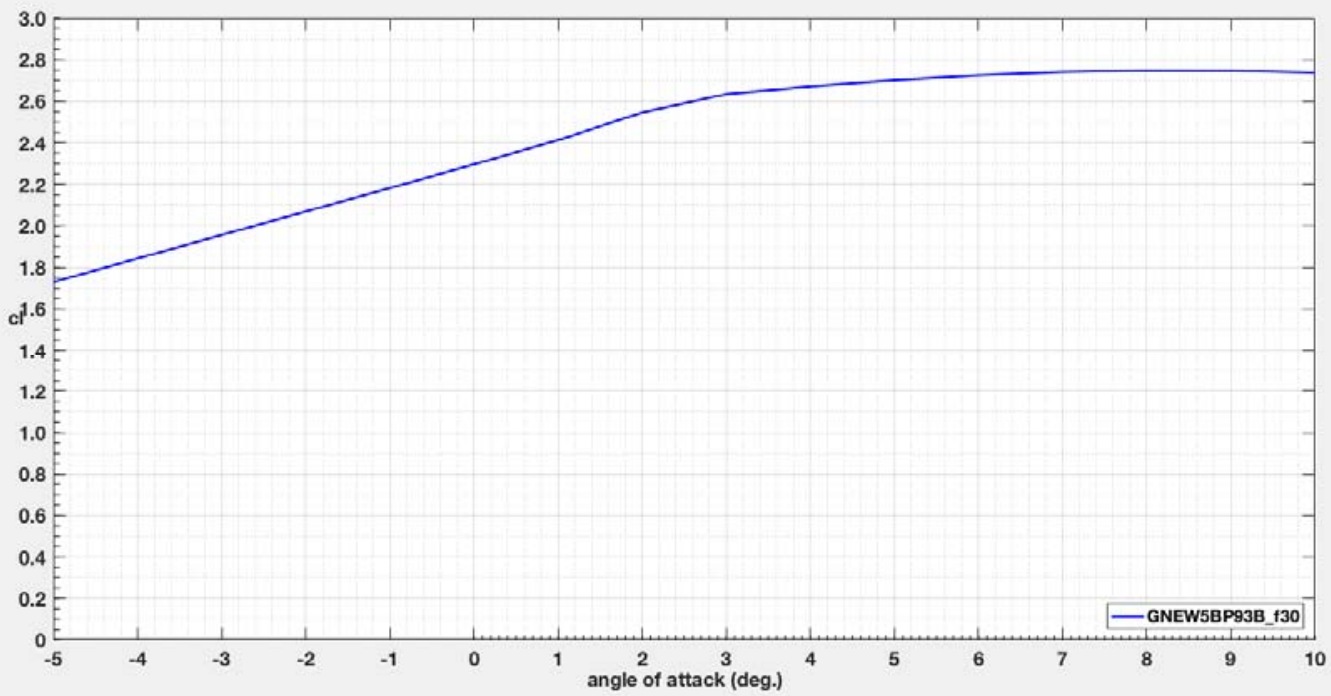

Figure 17a. Lift curve for the GNEW5BP93B airfoil with $25 \%$ chord flap deflected $30^{\circ}\left(M_{\infty}=0.096, R e=1.0\right.$ million, Ncrit=9). 
Denver, CO

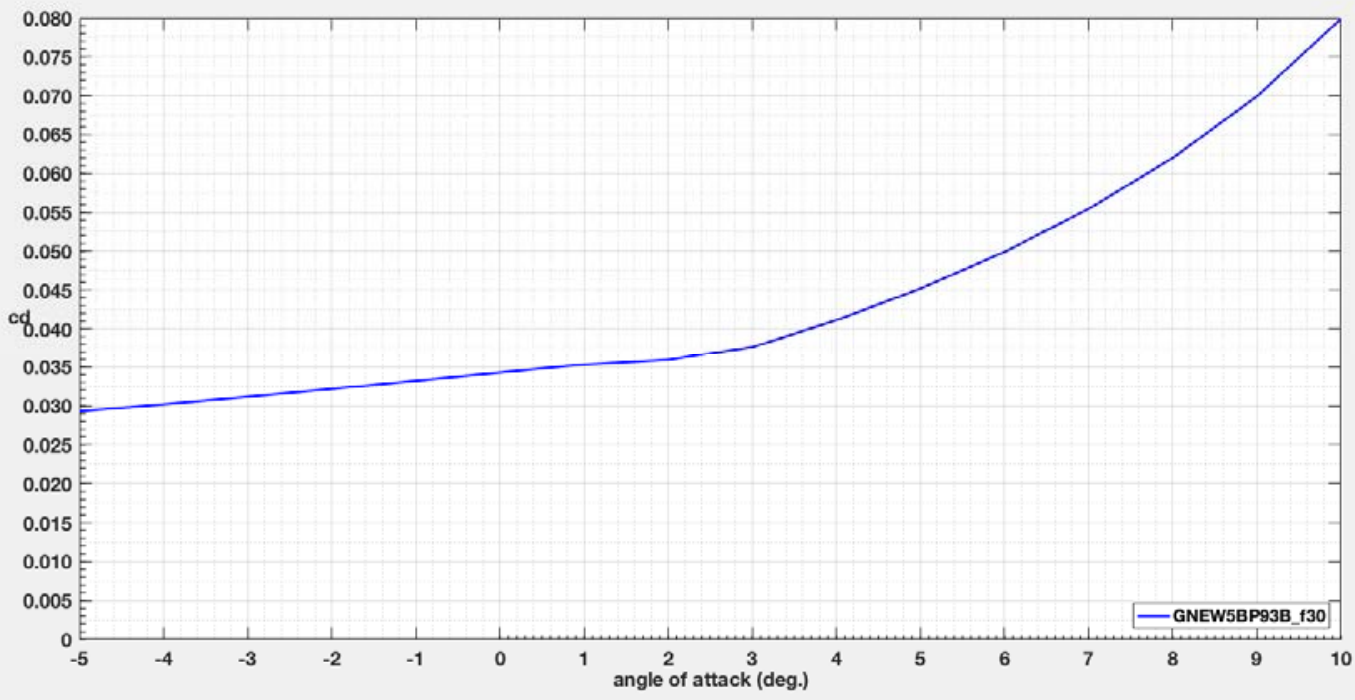

Figure 17b. Drag coefficient for the GNEW5BP93B airfoil with $25 \%$ chord flap deflected $30^{\circ}\left(M_{\infty}=0.096, R e\right.$ $=1.0$ million, Ncrit $=9$ ).

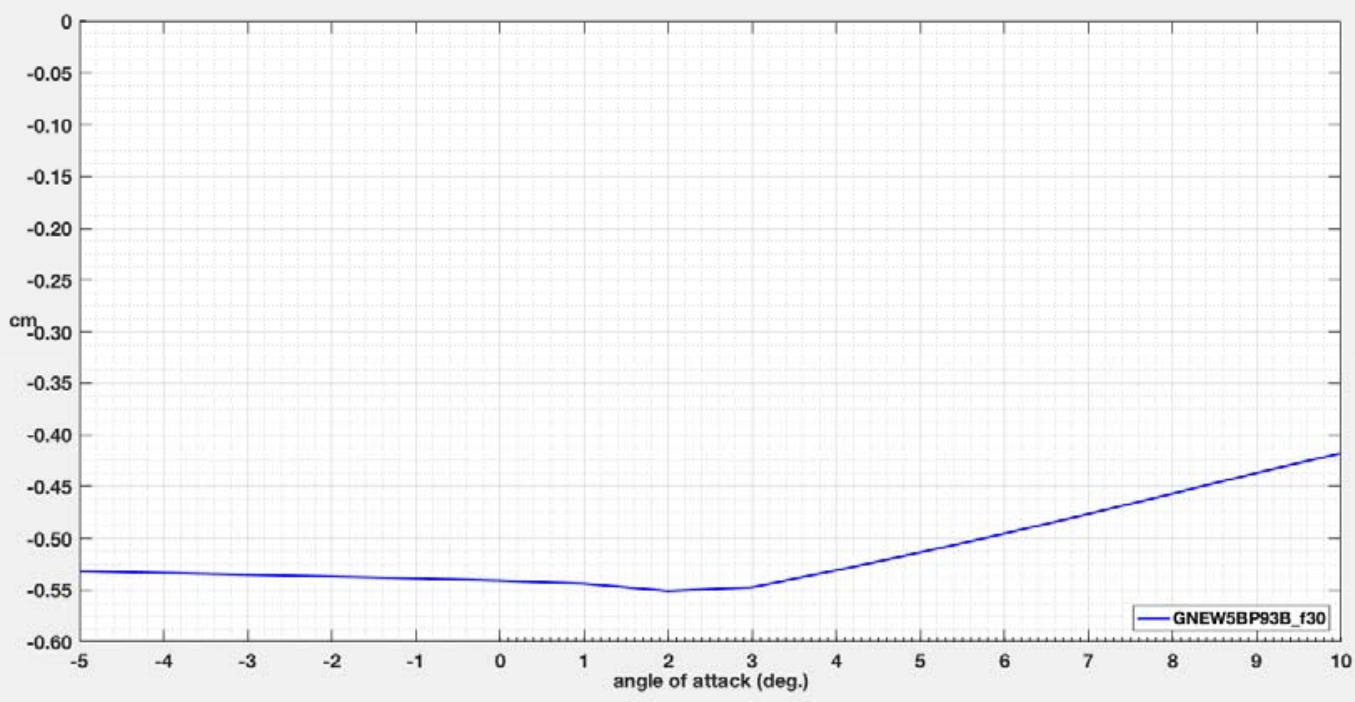

Figure 17c. Pitching moment coefficient for the GNEW5BP93B airfoil with $25 \%$ chord flap deflected $30^{\circ}\left(M_{\infty}\right.$ $=$ 0.096, $R e=1.0$ million, Ncrit $=9$ ). 
Denver, CO

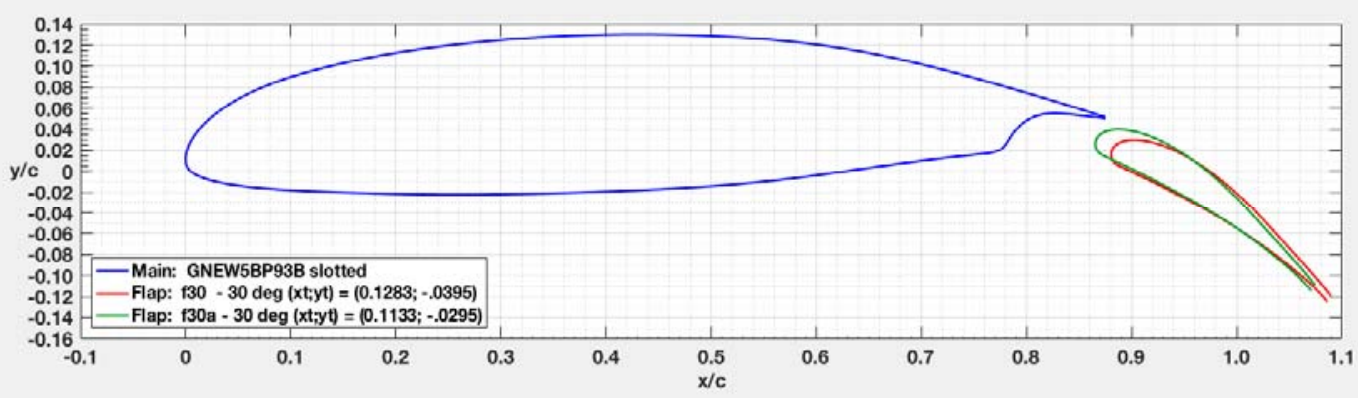

Figure 18a. GNEW5BP93B airfoil with $25 \%$ chord flap deflected $30^{\circ}$ (two gap/overlap locations shown).

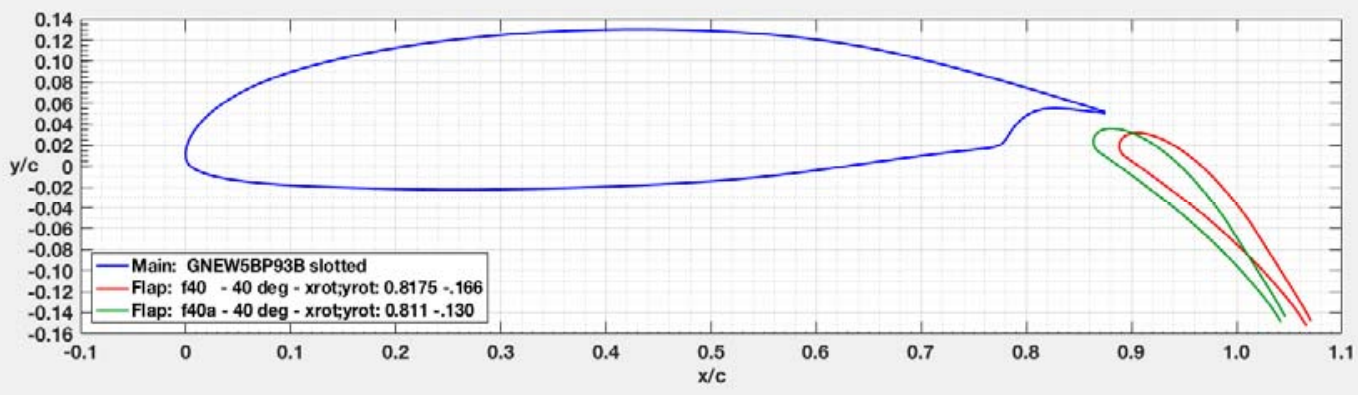

Figure 18b. GNEW5BP93B airfoil with $25 \%$ chord flap deflected $40^{\circ}$ (two gap/overlap locations shown). 
Denver, CO

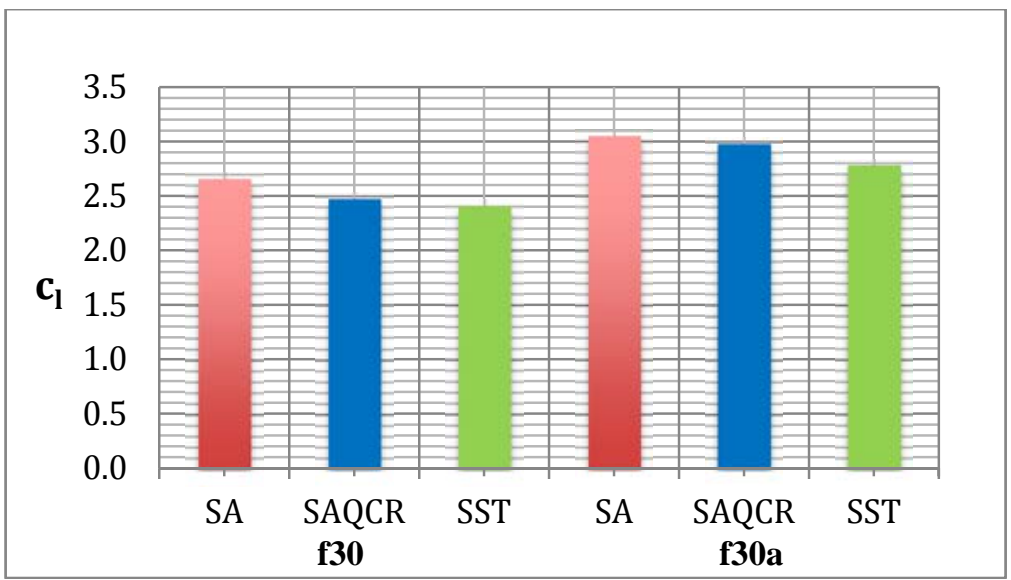

Figure 19a. Comparison of lift coefficients between turbulence models (SA, SAQCR, and SST) for the f30 and f30a airfoils at $M_{\infty}=0.096, R e=1$ million and $\alpha=6^{\circ}$. USM3D code.

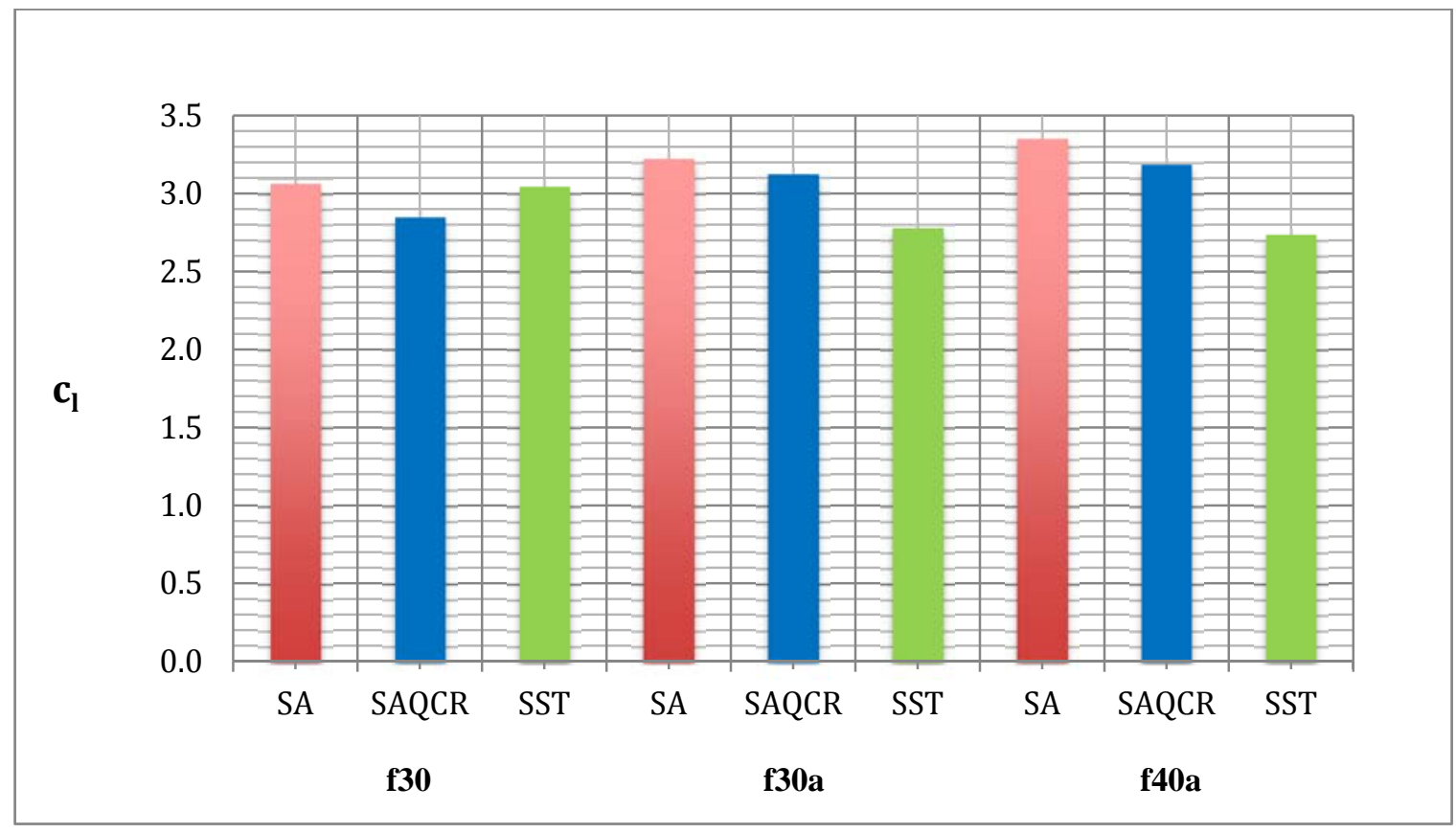

Figure 19b. Comparison of lift coefficients between turbulence models (SA, SAQCR, and SST) for the f30, f30a, and f40a airfoils at $M_{\infty}=0.096, R e=1$ million and $\alpha=10^{\circ}$. USM3D code. 
Denver, CO

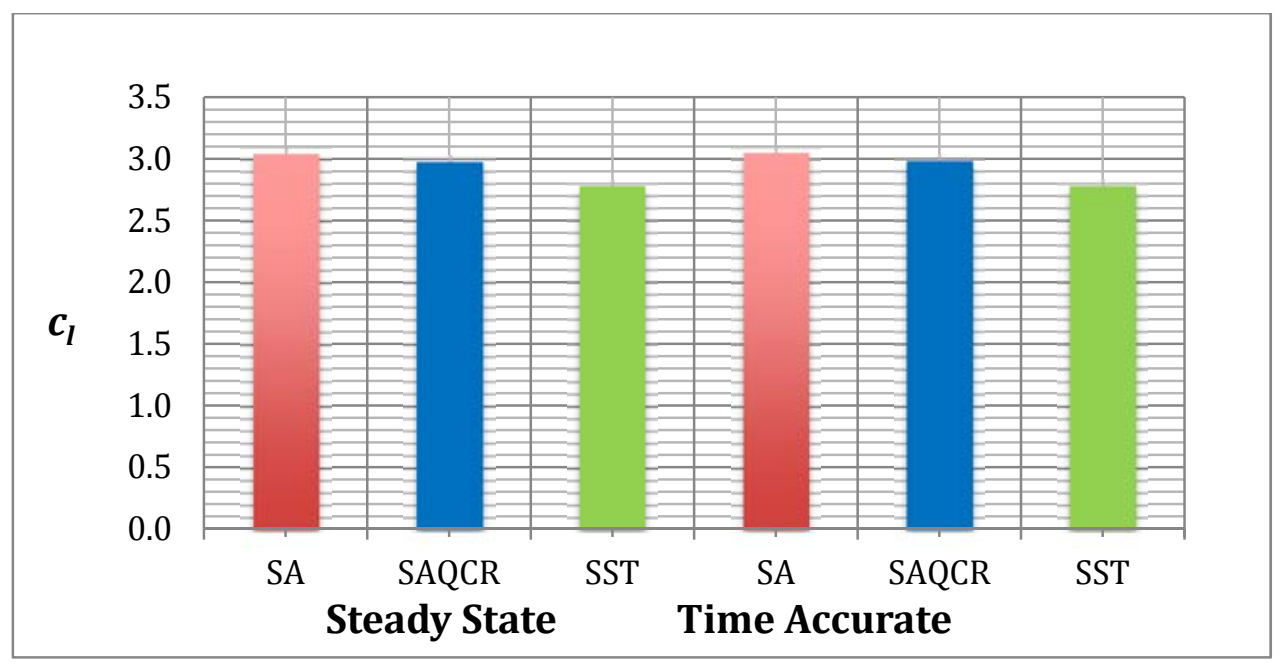

Figure 20. Comparison of lift coefficients between steady state and time accurate approaches for the SA, SAQCR, and SST turbulence models for the f30a airfoil at $M_{\infty}=0.096, R e=1$ million and $\alpha=6^{\circ}$. USM3D code. 
Denver, CO

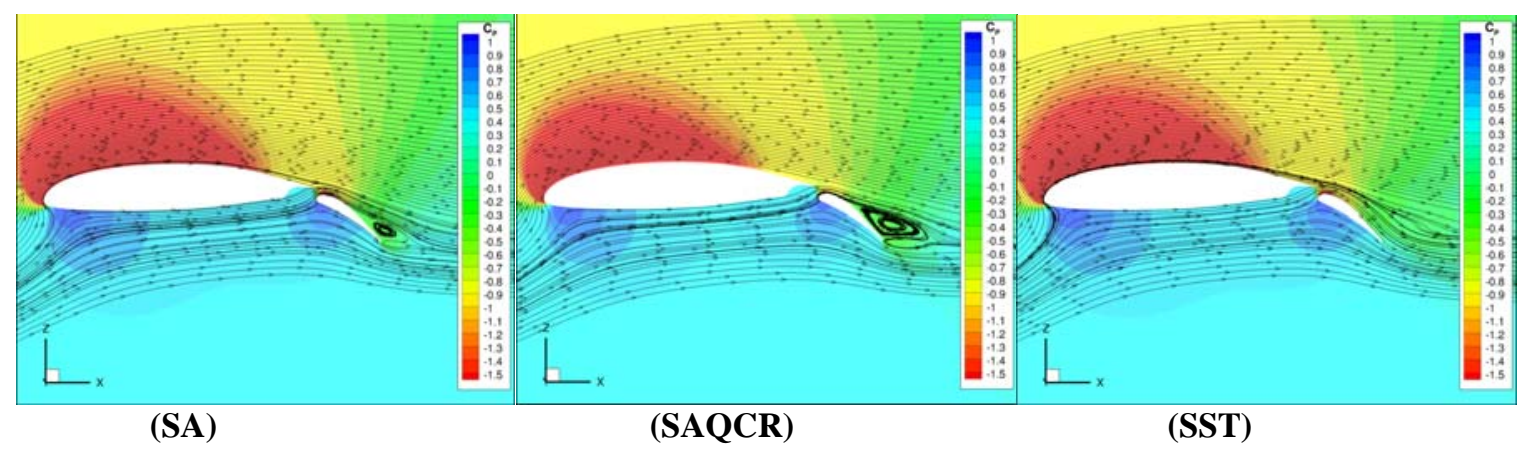

(a) f30 geometry

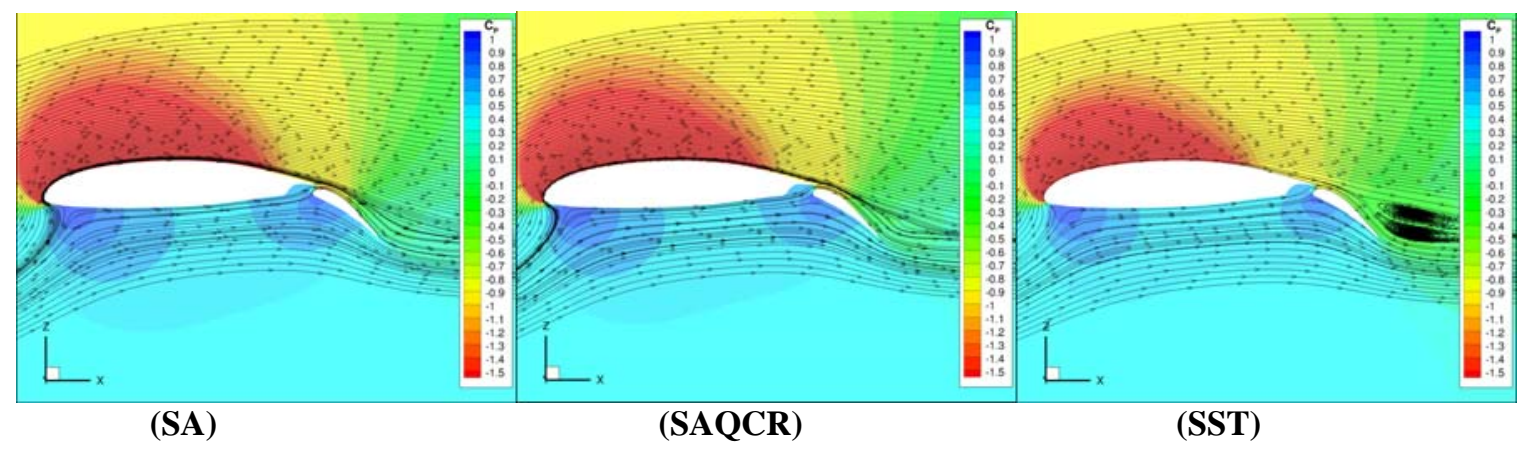

(b) f30a geometry

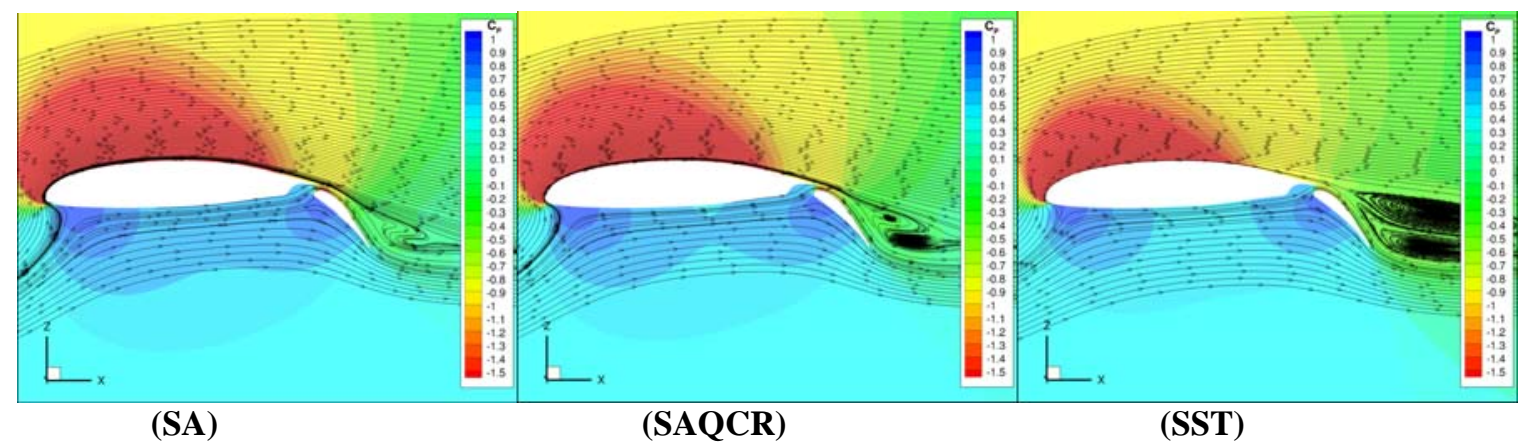

(c) f40a geometry

Figure 21. Pressure coefficient contour plots for the f30, f30a, and f40a geometries at $M_{\infty}=0.096, R e=1$ million, and $\alpha=10^{\circ}$ with SA(left), SAQCR (middle), and SST (right) turbulence models. USM3D code. 
Denver, CO

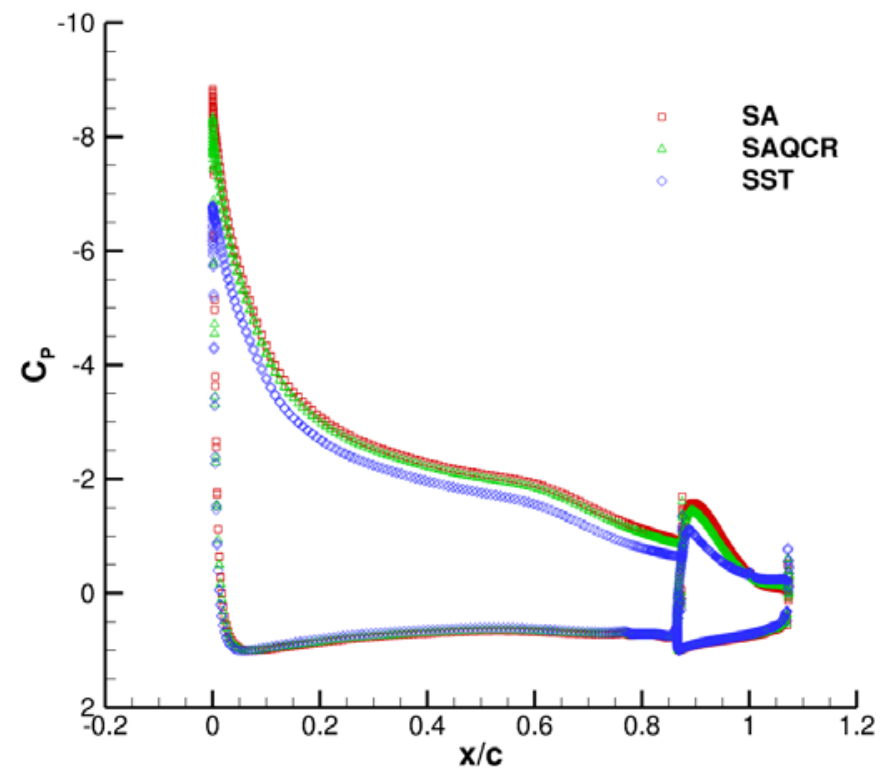

Figure 22. Pressure coefficient distributions along the f30a geometry at $M_{\infty}=0.096, R e=1$ million, and $\alpha=$ $10^{\circ}$, for the three turbulence models investigated (SA, SAQCR, and SST). USM3D code.

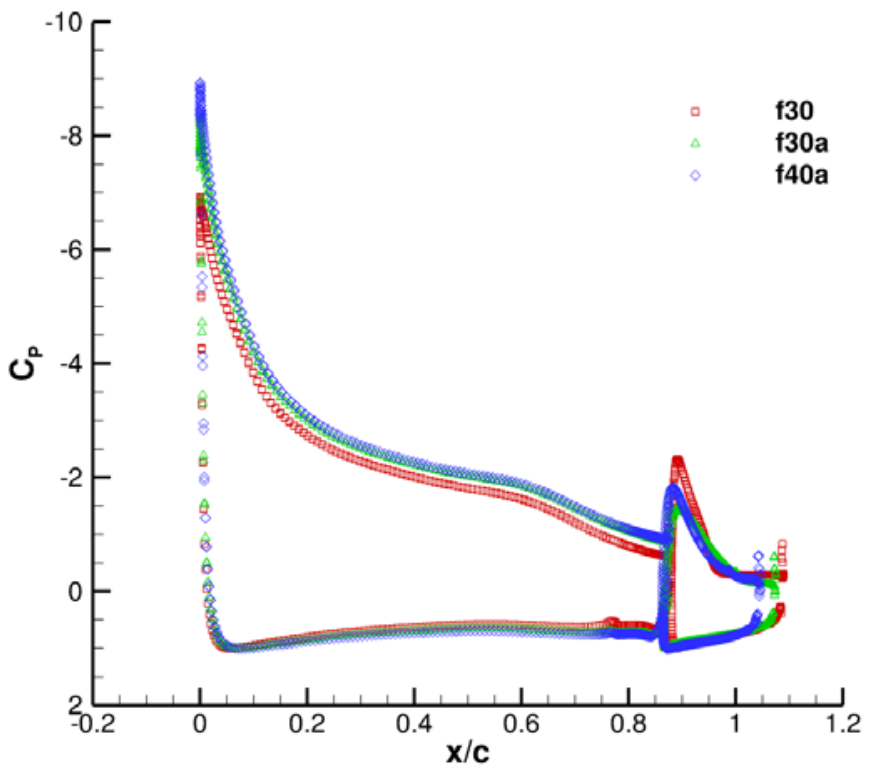

Figure 23. Pressure coefficient distributions along the f30, f30a, and f40a geometries at $M_{\infty}=0.096, R e=1$ million, and $\alpha=10^{\circ}$ with the SAQCR turbulence model. USM3D code. 
Denver, CO

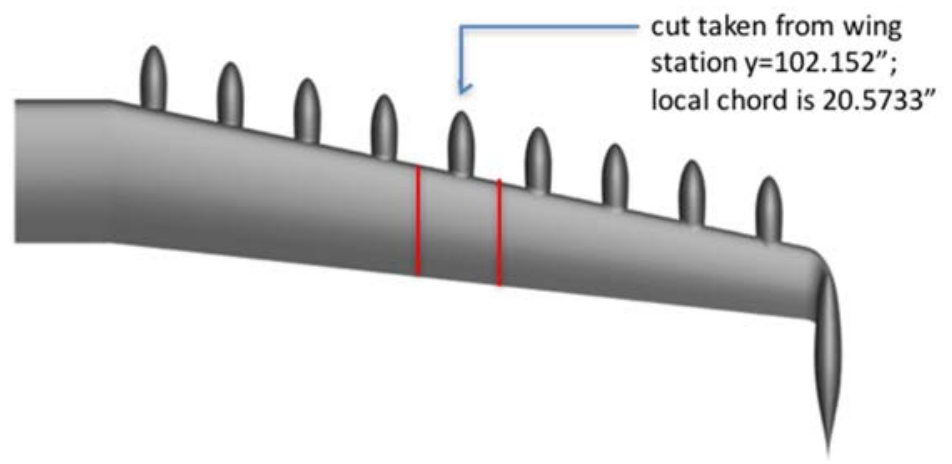

Figure 24. The HEIST wing without flap. (View shows where the section cut was taken from 3D wing; then taper removed)

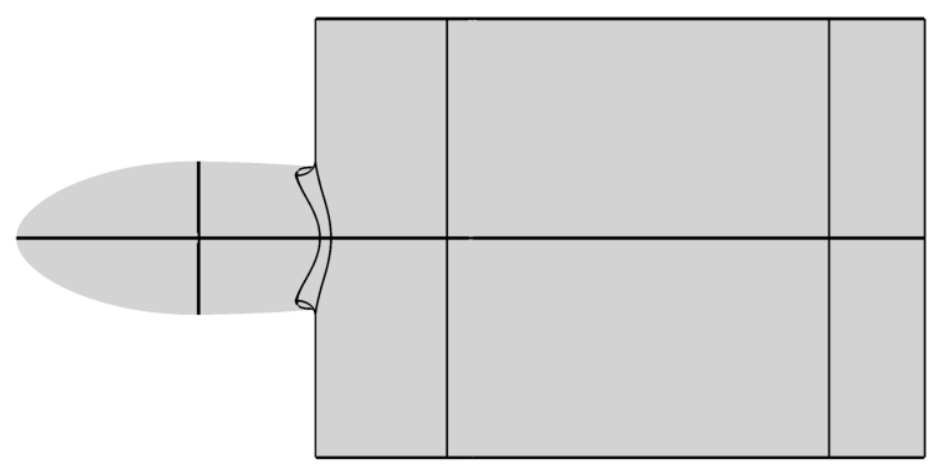

top view

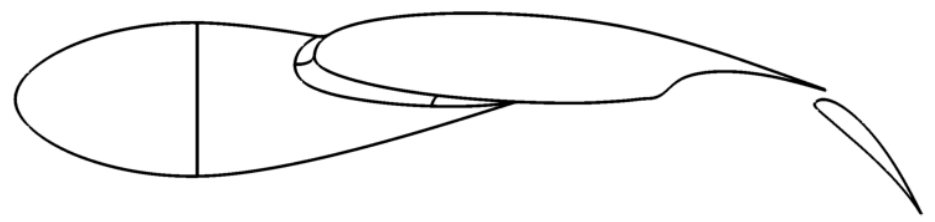

side view

Figures 25. Top and side view of the HEIST GAW-1 airfoil section cut with $40^{\circ}$ flap deflection and high-lift nacelle (constant chord, taper removed; patch boundaries shown). 


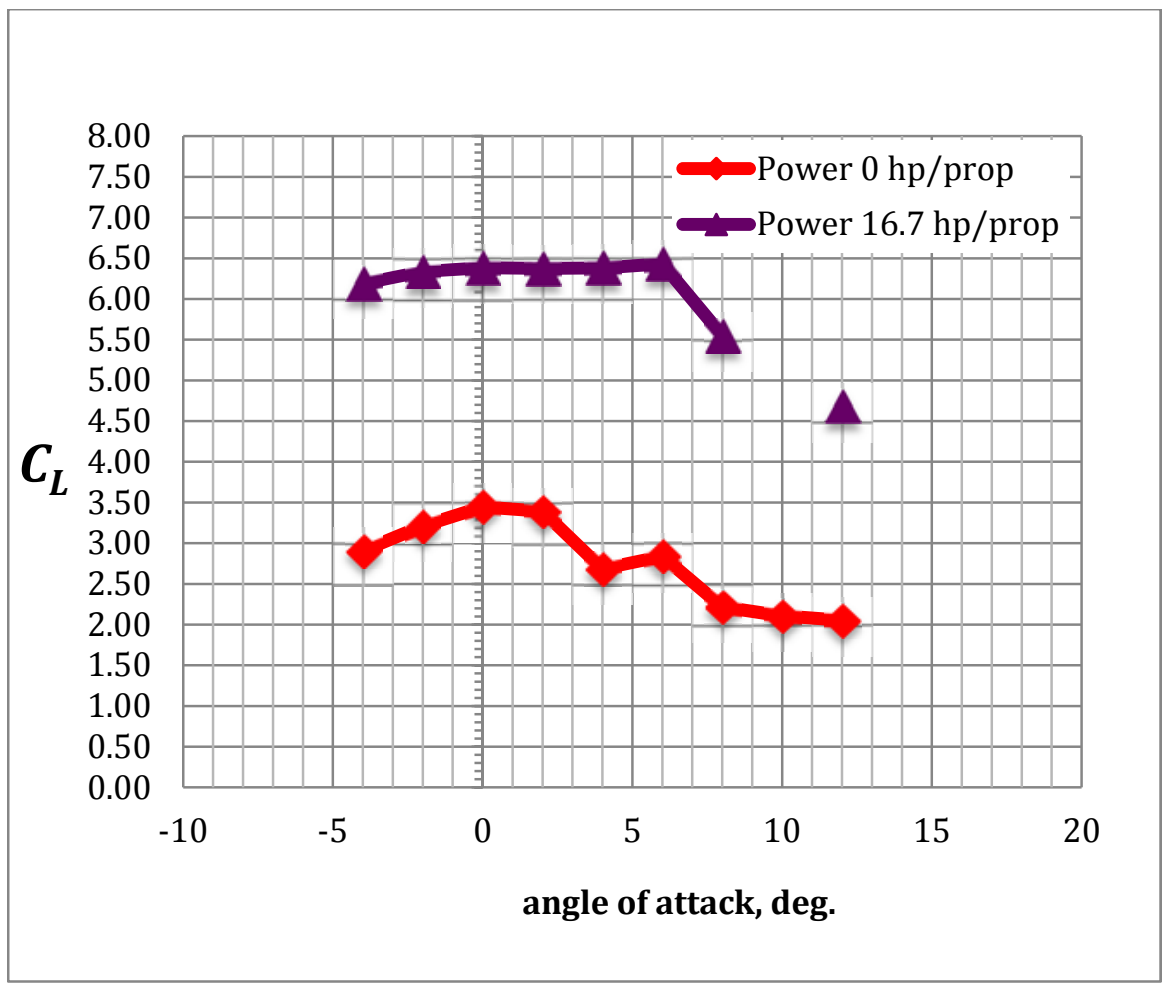

(a) lift coefficient

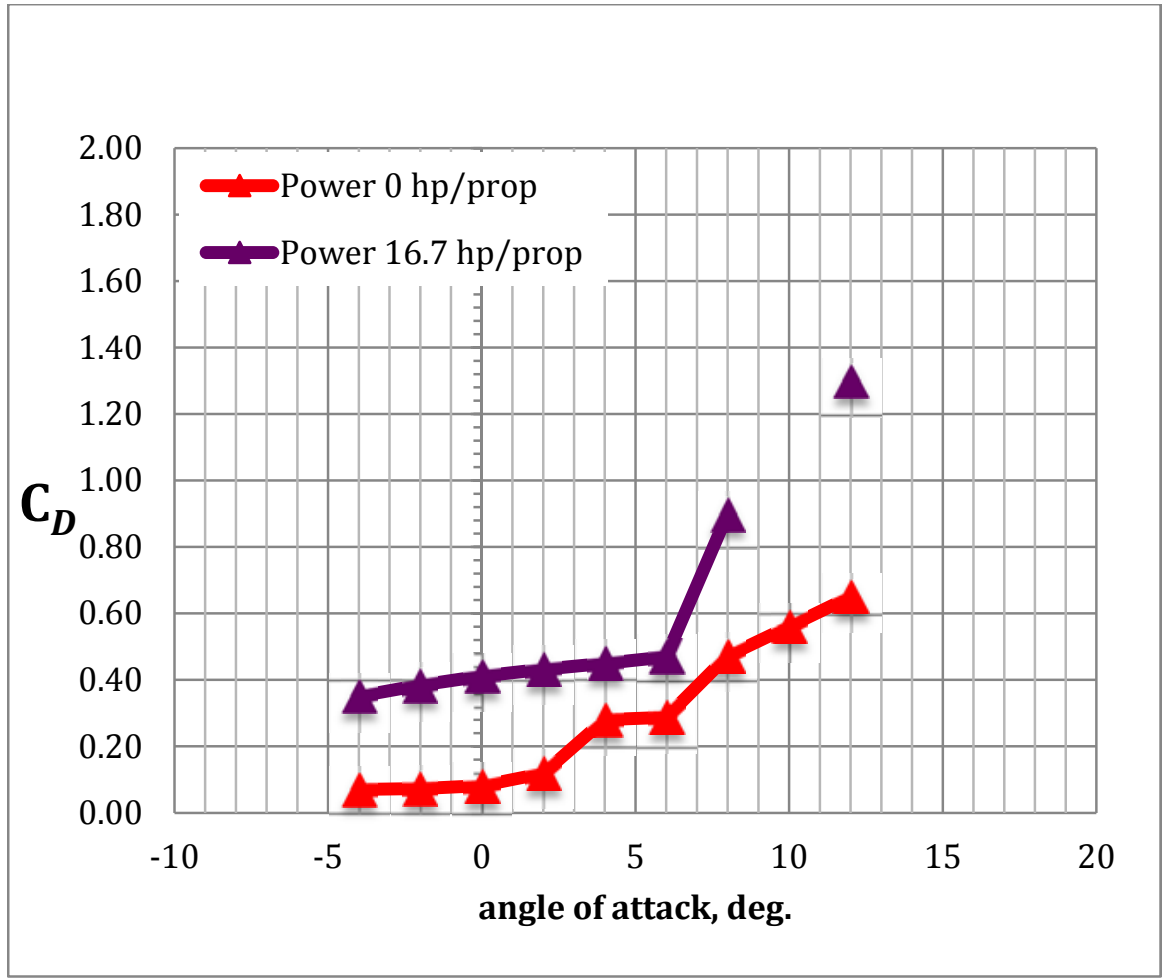

(b) drag coefficient 
Denver, CO

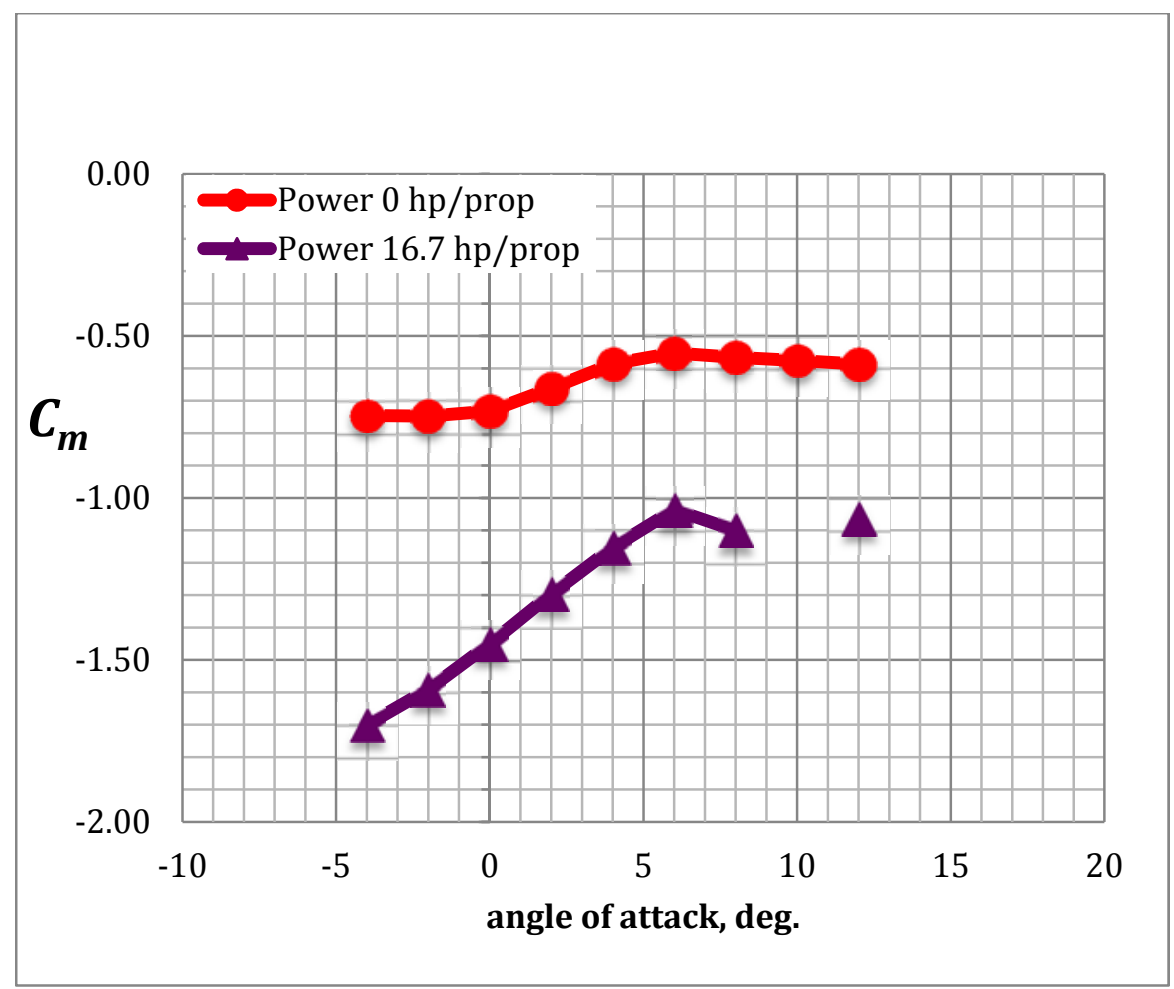

(c) pitching moment coefficient

Figure 26. FUN3D Navier-Stokes solutions of the HEIST GAW-1 airfoil section with $40^{\circ}$ flap deflection and high-lift nacelle with and without blowing $(16.7 \mathrm{hp} / \mathrm{prop})$ for $M_{\infty}=0.0962$ and $R e=1$ million. Note, the wing incidence of $3.5^{\circ}$ is not reflected in the angle of attack). SARC+QCR turbulence model.

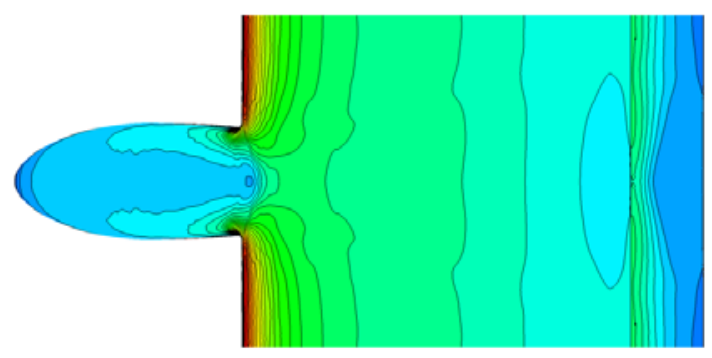

$C_{p}-8.0-7.6-7.2-6.9-6.5-6.1-5.8-5.4-50-4.6-42-3.9-3.5-3.1-2.8-2.4-2.0-1.6-1.2-0.9-0.5-0.10 .20 .61 .0$

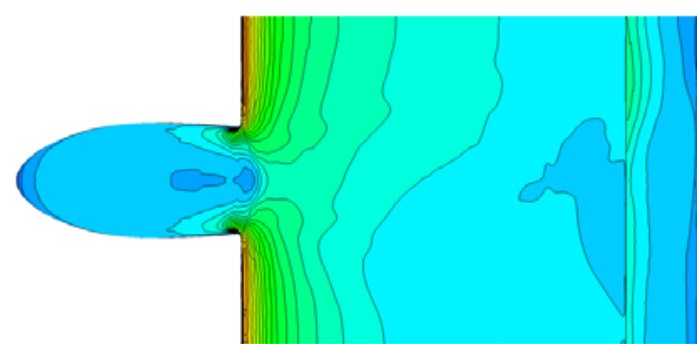

$C_{p} \cdot 8.0 \cdot 7.6 \cdot 7.2 \cdot 6.9 \cdot 6.5 \cdot 6.1 \cdot 5.8 \cdot 5.4 \cdot 5.0 \cdot 4.6 \cdot 4.2 \cdot 3.9 \cdot 3.5 \cdot 3.1 \cdot 2.8 \cdot 2.4 \cdot 2.0 \cdot 1.6 \cdot 1.2-0.9 \cdot 0.5 \cdot 0.10 .20 .61 .0$

Figure 27a. Upper surface pressure coefficient contour plots of the unblown HEIST wing section with $40^{\circ}$ flap deflection for $M_{\infty}=0.0962, R e=1$ million, at $\alpha=0^{\circ}$ (left) and $\alpha=4^{\circ}$ (right). FUN3D with SARC+QCR turbulence model. 
Denver, CO
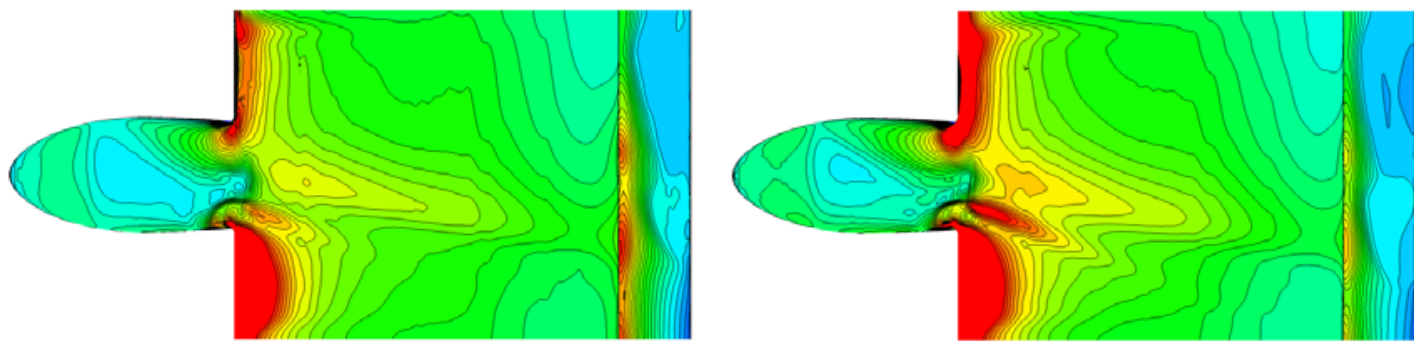

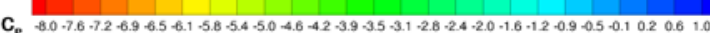

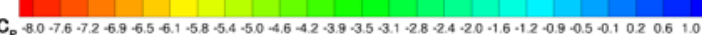

Figure 27b. Upper surface pressure coefficient contour plots of the blown (16.7 hp/prop) HEIST wing section with $40^{\circ}$ flap deflection for $M_{\infty}=0.0962, R e=1$ million, at $\alpha=0^{\circ}$ (left) and $\alpha=4^{\circ}$ (right). FUN3D with SARC+QCR turbulence model.

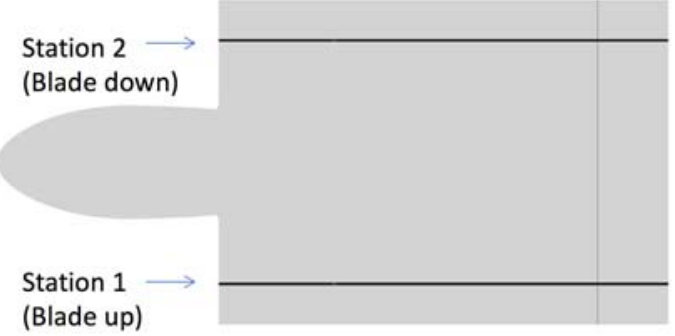

Figure 28. Top view representing Station 1 (blade up) and Station 2 (blade down) locations where pressure coefficient distributions are taken for HEIST wing section with $40^{\circ}$ flap deflection.

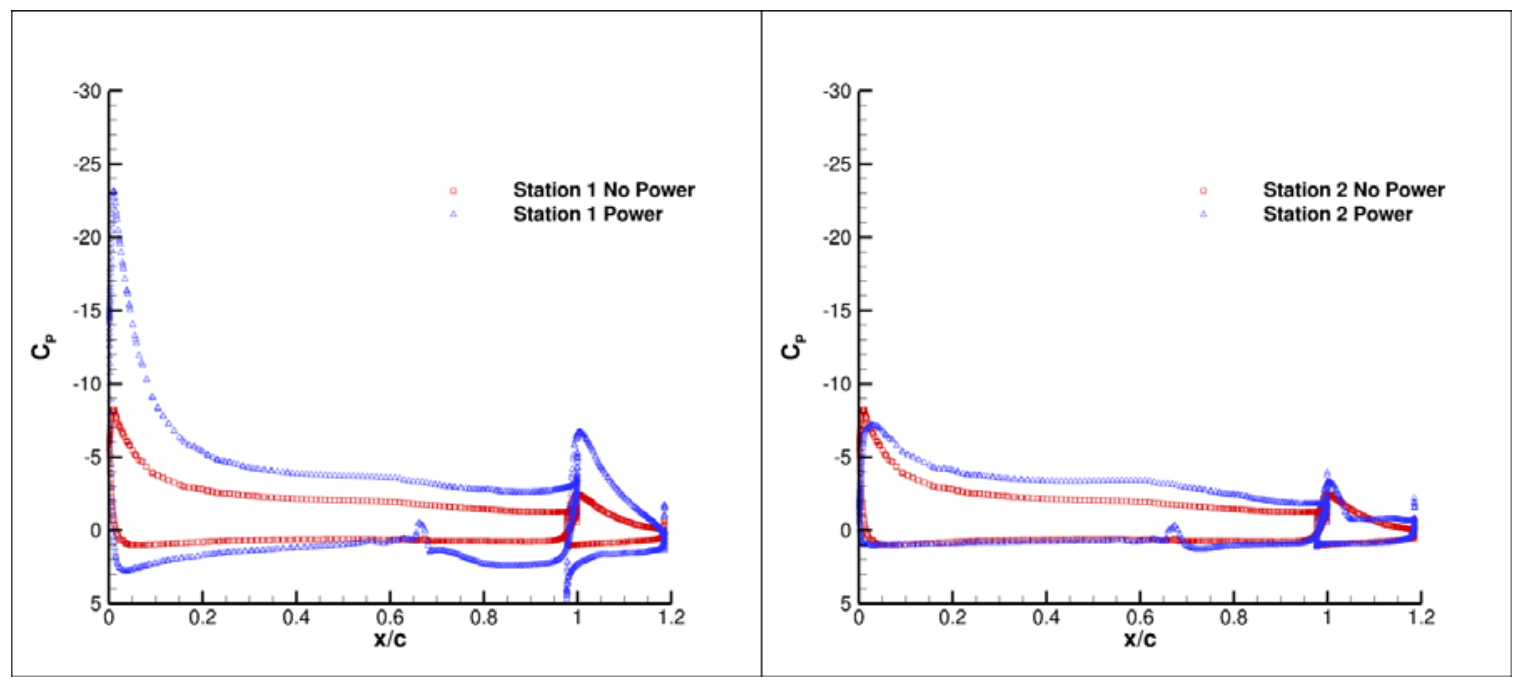

(a) $\alpha=0^{\circ}$ 


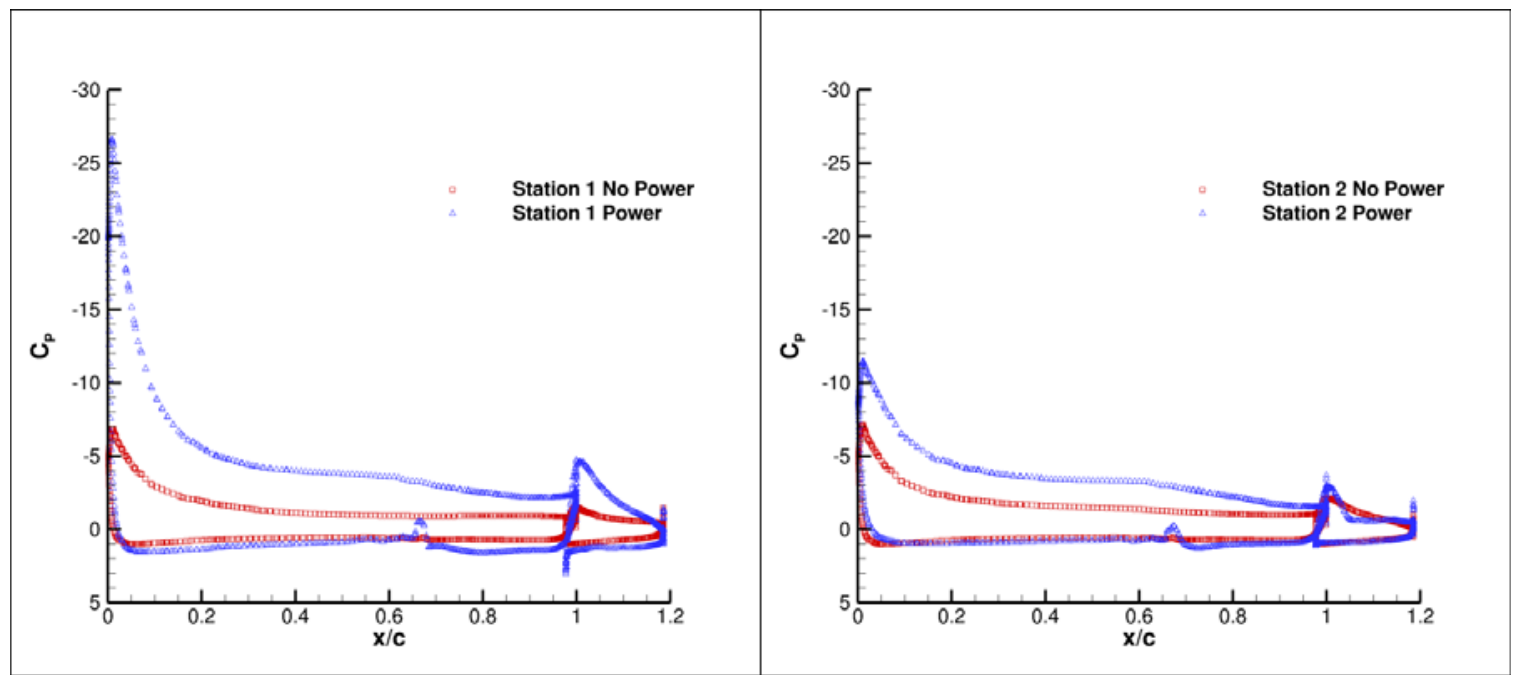

(b) $\alpha=4^{\circ}$

Figure 29. Station 1 (blade up) and Station 2 (blade down) pressure coefficient distributions at $M_{\infty}=$ 0.0962 and $R e=1$ million for $\alpha=0^{\circ}$ and $4^{\circ}$ for the unblown (no power) and blown (16.7 hp/prop) HEIST wing section with $40^{\circ}$ flap deflection. FUN3D with SARC+QCR turbulence model.
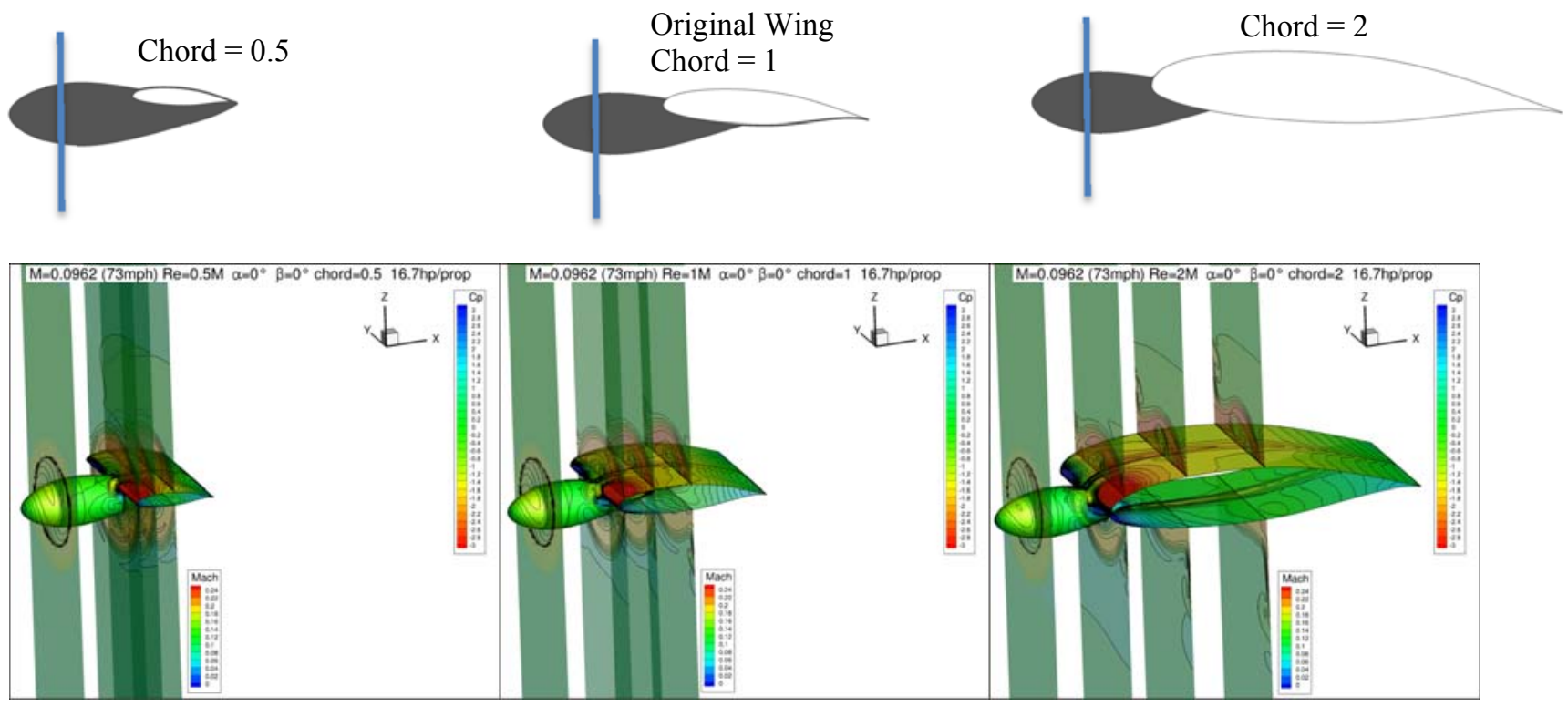

Figure 30. Side view of each HEIST cruise wing section, along with oblique views of pressure coefficients and Mach contour planes, at $M_{\infty}=0.0962$ and $\alpha=0^{\circ}$, for $R e=0.5$ million $\left(c_{\text {ref }}=0.5\right), \operatorname{Re}=1$ million $\left(c_{\text {ref }}=1\right)$, and $R e=2$ million $\left(c_{r e f}=2\right)$ with blowing $(16.7 \mathrm{hp} /$ prop$)$. FUN3D with SARC+QCR turbulence model. 
Denver, CO

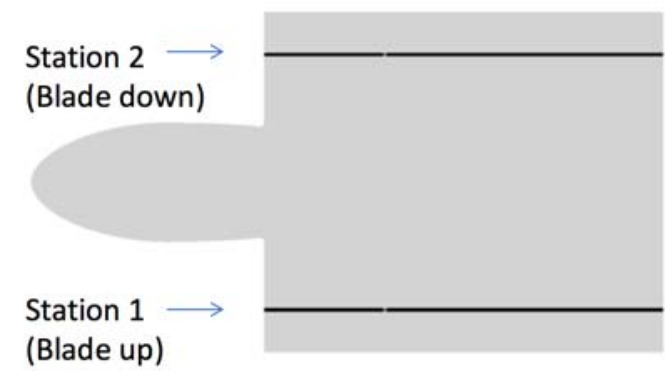

Figure 31. Top view representing Station 1 (blade up) and Station 2 (blade down) locations where pressure coefficient distributions are taken for HEIST cruise wing section with high-lift nacelle.

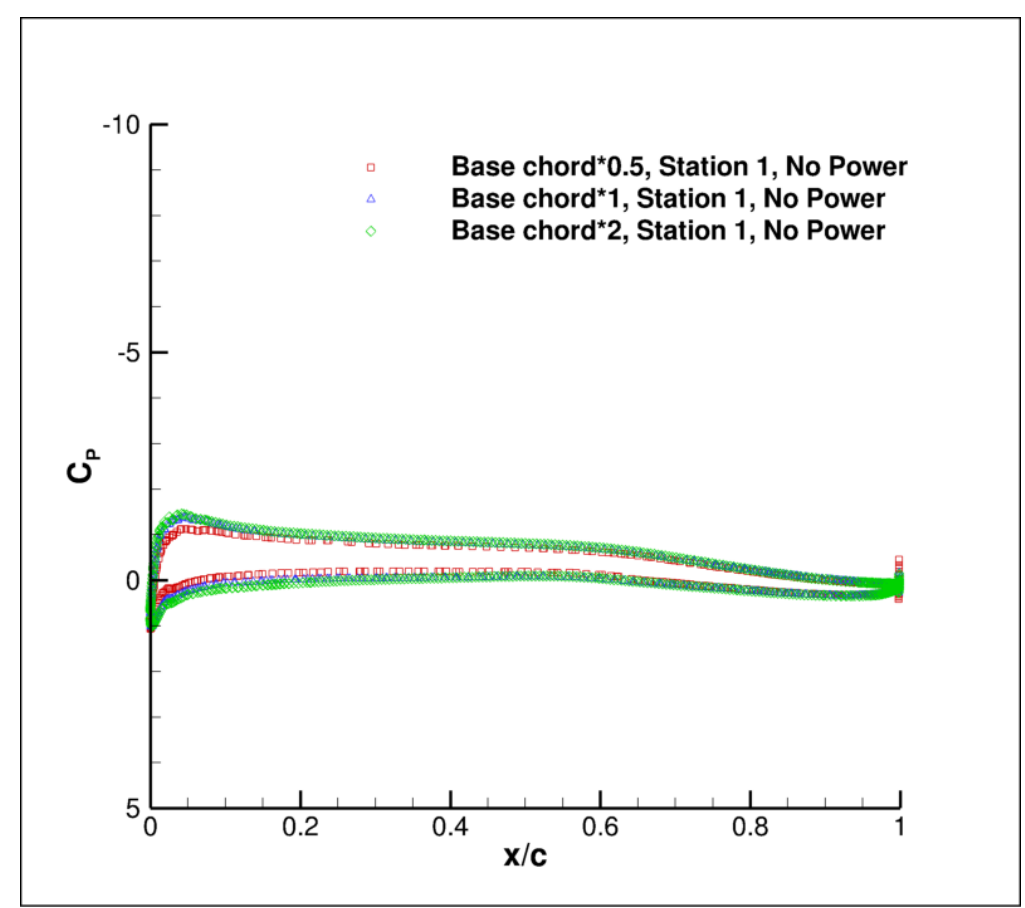

(a) Station1, Unblown Wing 
Denver, CO

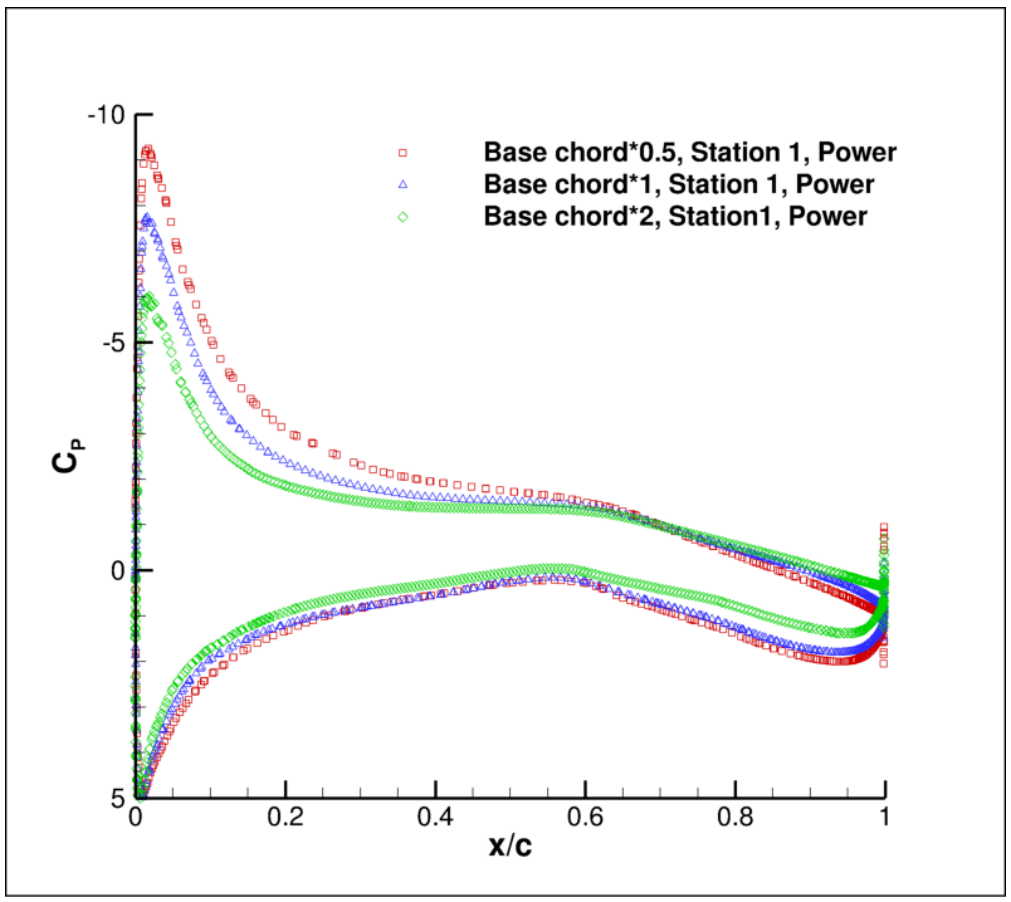

(b) Station 1, Blown Wing

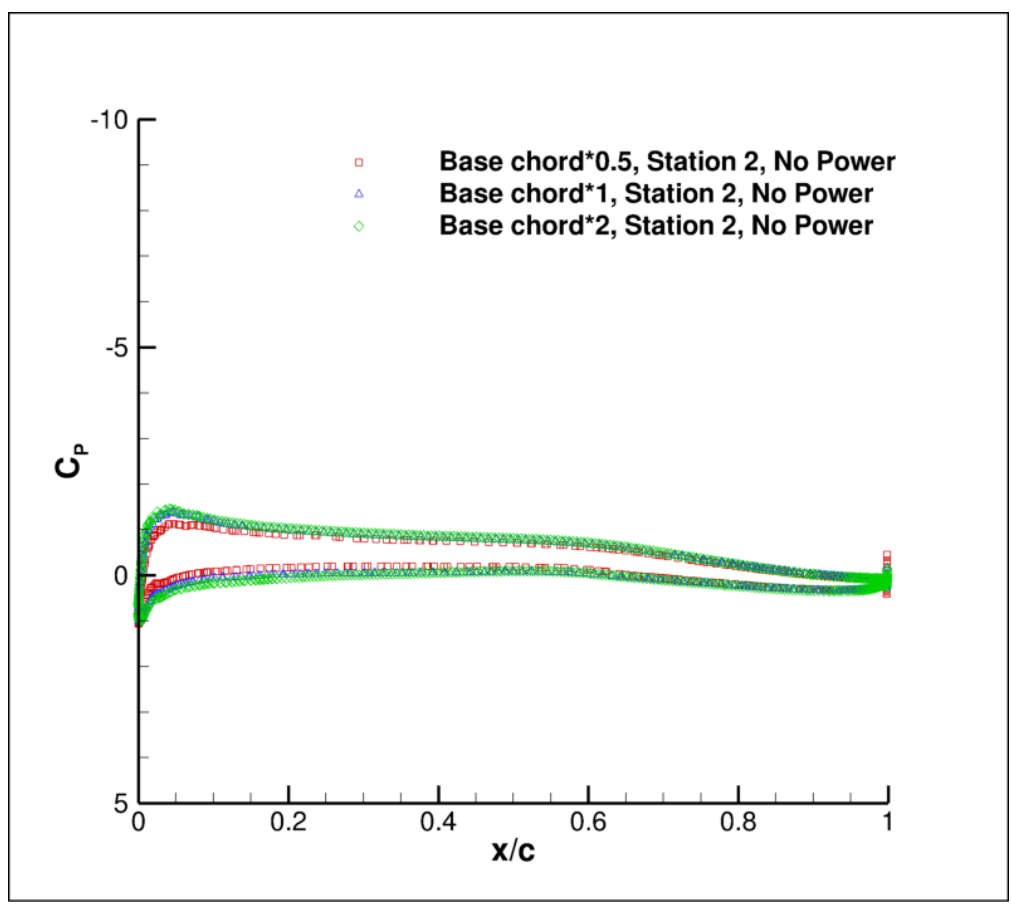

(c) Station 2, Unblown Wing 
Denver, CO

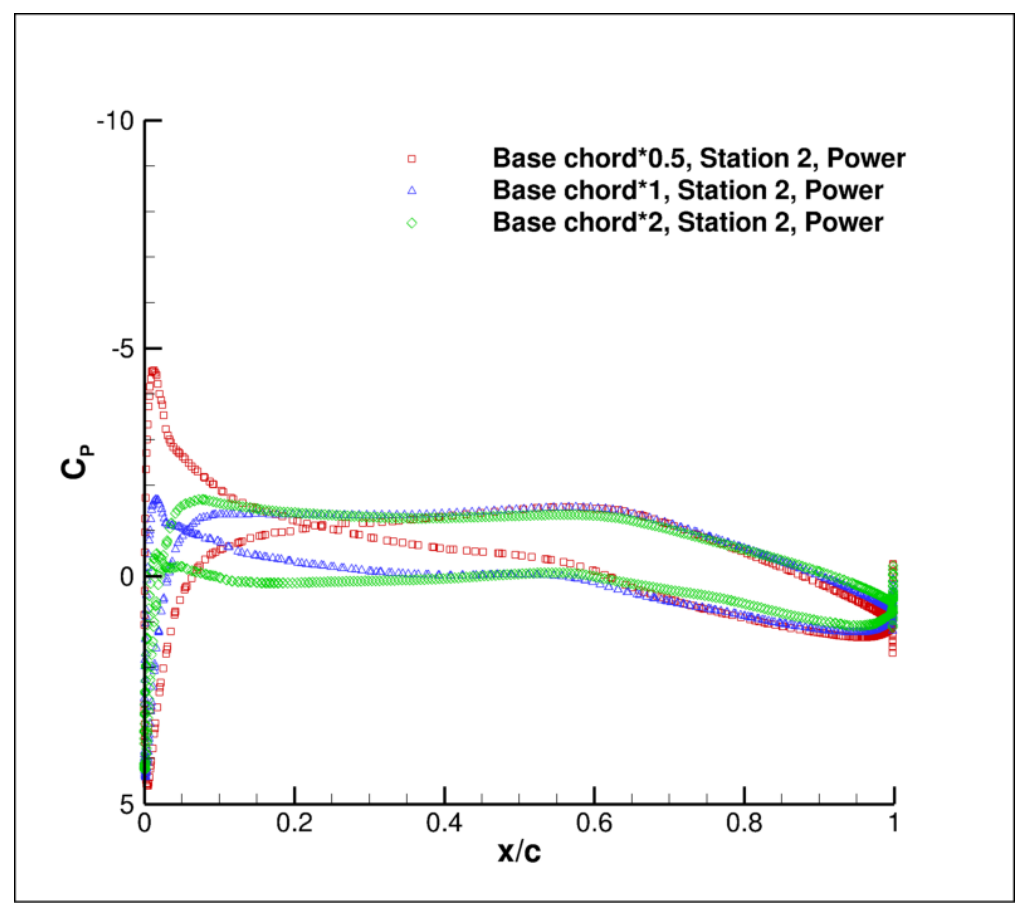

(d) Station 2, Blown Wing

Figure 32. Station 1 (blade up) and Station 2 (blade down) pressure coefficient distributions at $M_{\infty}=0.0962$ and $\alpha=0^{\circ}$ for unblown and blown (16.7 hp/prop) HEIST cruise wing. Base chord $* 0.5$ at $R e=0.5$ million; Base chord at $R e=1$ million; and Base chord $* 2$ at $R e=2$ million. FUN3D with SARC+QCR turbulence model. 